\title{
The Price of Gold: Dowry and Death in India*
}

\author{
Sonia Bhalotra ${ }^{\dagger}$ \\ Abhishek Chakravarty $\ddagger$ \\ Selim Gulesci §
}

July 20, 2019

\begin{abstract}
We provide evidence that dowry costs motivate son-preferring behaviors in India. Since gold is an integral part of dowry, we study parental responses to shocks in the world gold price. Exploiting monthly variation in gold prices across 35 years we find that monthly changes in gold prices lead to an increase in girl relative to boy neonatal mortality and that surviving girls are shorter. After the introduction of prenatal sex determination technology, we find that gold price shocks during pregnancy increase female foeticide.
\end{abstract}

Keywords: dowry, gold, son preference, missing girls, neonatal mortality, commodity price shocks

JEL codes: I14, J16, O12

\footnotetext{
*The paper has benefited greatly from the suggestions of the Editor Chris Udry and two anonymous referees. We would like to thank the following colleagues for helpful discussions- Siwan Anderson, Alison Andrew, Jean-Marie Baland, Abhijit Banerjee, Konrad Burchardi, Guilhem Cassan, Lucia Corno, Pascaline Dupas, Mukesh Eswaran, James Fenske, Eliana La Ferrara, Sara Lowes, Giovanni Mastrobuoni, Kaivan Munshi, Nicola Pavoni, Debraj Ray, Mark Rosenzweig, Sanchari Roy, Alessandro Tarozzi, Selma Telalagic Walther, Diego Ubfal, Alessandra Voena. We received helpful comments from participants at the Royal Economic Society Conference 2013, 9th ACEDG Conference at the Indian Statistical Institute, NEUDC 2014, "Families and the Macroeconomy Conference" at Edesheim, IFS EDEPO Conference 2015, EUDN Conference 2015, 31st BREAD Conference, as well as seminar participants at Graduate Institute Geneva, Oxford CSAE, Trinity College Dublin, Maynooth University, Bocconi University and the University of Essex. Sonia Bhalotra acknowledges partial funding from the ESRC Centre Grant ES/L009153/1 awarded to the Research Centre for Micro-Social Change at ISER, Essex. All errors are our own.

${ }^{\dagger}$ Department of Economics and ISER, University of Essex. Email: srbhal@essex.ac.uk.

${ }^{\ddagger}$ Department of Economics, University of Manchester. Email: abhishek.chakravarty@manchester.ac.uk.

$\S$ Department of Economics and IGIER, Bocconi University. Email: selim.gulesci@unibocconi.it.
} 


\section{Introduction}

Dowry, a transfer of parental property at the marriage of a daughter, is an ancient tradition thought to date back to at least $200 \mathrm{BCE}$, and widely prevalent in medieval western Europe. ${ }^{1}$ While this tradition has virtually disappeared with modernization in most of the rest of the world, it persists in contemporary India and has become increasingly common in Bangladesh, Pakistan, and Sri Lanka. Although systematic time series data on dowry payments are scarce, sample surveys indicate that they are rising. ${ }^{2}$

Dowry is often adduced as a motivation for son-preference in India (Miller (1981), Harris (1993), M. Das Gupta et al. (2003)). ${ }^{3}$ Dowry is a considerable tax on girls' families, with estimates indicating that it is often 4 to 8 times annual household income (Anderson (2007), Rao (1993)). Families appear to start saving for dowry as soon as a girl is born (Browning and Subramaniam (1995), Anukriti et al. (2017)), and when income constrained may be forced to sell productive assets including land in order to afford dowry payments (Gupta (2002), Kodoth (2005)). While the original dowry payments acted as a pre-mortem bequest to daughters that afforded them post-marital financial protection, property rights over dowry are now often appropriated by the groom or his parents rather than retained by the bride, and this tendency appears to be increasing, at least initially, in economic development (Anderson and Bidner (2015)).

Overall, dowry in India tends to impoverish families with daughters, increasing the cost of having a daughter. This makes it plausible that dowry costs motivate a preference for having sons, and several previous studies implicate dowry (Arnold et al. (1998), Miller (1981), Harris (1993), M. Das Gupta et al. (2003)). Borker et al. (2017) argue that son preference emerges from marriage market imperfections, as does dowry, even when there is no son preference in the utility function. Our contribution is to provide what we believe is the first clear evidence of causal effects of dowry costs on son preferring behaviours.

Perhaps because dowry has been prohibited in India since 1961, data on dowry have been largely unavailable and this is no doubt a reason for the scarcity of previous work. However, even if data on dowry payments were widely available, researchers would need to address the problem that they vary endogenously with family preferences and characteristics including

\footnotetext{
${ }^{1}$ Surveys of historical research are provided in Anderson (2003), Botticini and Siow (2003)), Hughes (1978), Tambiah and Goody (1973).

${ }^{2}$ On the prevalence of dowry in India, see Anderson (2007), and the Survey of Status of Women and Fertility (SWAF) 1993-94 which indicates that as many as 90\% of marriages involve bridal dowry (Smith et al. (2000)). Dowry inflation is discussed in Rao (1993) and Anderson (2003).

${ }^{3}$ Possibly competing explanations include funeral procedures, old age security and gendered labour market opportunities and returns.
} 
wealth, education and caste in micro-data, ${ }^{4}$ and with population sex ratios in time series data (Rao (1993), Edlund (2000)).

We avoid these problems by using plausibly exogenous variation in the burden of dowry created by variation in gold prices on the world market. India has historically imported more than $90 \%$ of its gold stocks, making the international price relevant (Reserve Bank of India (2013)). Gold, typically in the form of jewellery, is an integral part of dowry in India. Our hypothesis is that gold price shocks signify an increase in the cost of dowry, raising the cost of daughters (and also lowering the cost of sons, as they will bring in dowry). A necessary condition is that the quantities of gold given in dowry do not fully adjust to changes in the price of gold, so that price changes lead to changes in dowry costs. Using rare survey data that contain dowry values and the year of marriage, and merging in gold prices, we are able to test this. We find that the elasticity of dowry value to the average gold price during the year of marriage is 0.78 to 0.85 (depending on controls) and statistically significant. This establishes both the importance of gold in dowry, and that dowry values co-vary with gold prices. $^{5}$

We use monthly time series data for 1972-2005 and estimate girl and boy neonatal mortality rates as a function of gold price shocks. We find that more girls die soon after birth in months in which international gold prices are rising. At the same time we see a tendency for boy mortality to decline.

The availability of prenatal sex diagnostics (in particular, ultrasound scanners) since the mid-1980s has led to sex-selective abortion on a wide scale, a means of eliminating girls earlier in life (Bhalotra and Cochrane (2010)). Girls who survive to birth among post-1985 birth cohorts are more wanted girls, who receive more equal investments (Anukriti et al. (2015); Section 2 below). To account for this structural break in son-preference behaviour, we divided the long time series data at 1985 . We find that the increase in girl neonatal mortality in the full sample emerges mainly from the pre-1985 period. Among post-1985 births, we find that systematically fewer girls are born in months of gold price inflation, consistent with parents adjusting the sex ratio of surviving births pre- rather than post-natally. ${ }^{6}$

During 1972-1985, a one standard deviation change in monthly gold price inflation (which was 0.063 ) was associated with a statistically significant increase in girl neonatal mortality of 0.27 percentage points (or 6.4 percent), and a decrease in boy mortality of 0.23 percentage

\footnotetext{
${ }^{4}$ See Bloch and Rao (2002), Deolalikar and Rao (1998), and controls in Table 2 in this paper (estimates available upon request).

${ }^{5}$ In line with this, Vaidyanathan (1999) shows that the demand for gold in India is price inelastic. As far as we are aware, the elasticity of dowry to gold prices has not been estimated before. Therefore, a secondary contribution of our paper is providing an estimate of the gold price elasticity of dowry value.

${ }^{6}$ There is no discernible relationship in the pre-1985 period. This acts as a placebo test since there were limited opportunities to detect fetal sex before 1985 .
} 
points. We also find that a one s.d. change in gold price inflation in the birth year (which is 0.202 ) is associated with women being $0.1 \mathrm{~cm}$ shorter in early adulthood. The corresponding estimates for men are smaller and statistically not different from zero. This result supports the mechanism of parental neglect as a driver of excess female mortality after birth for these cohorts given evidence that adult stature is sensitive to childhood nutrition (Bozzoli et al. (2009), Akresh et al. (2012)).

During 1986-2005, gold price changes created no significant change in neonatal mortality, but a one s.d. increase in gold price inflation (which, in this period, is 0.026) results in an approximately 0.3 percentage point decline in the probability that a girl rather than a boy is born, which is about a fourth of the estimated trend decline.

Our findings are robust to several specification checks, including using month-by-year fixed effects. These absorb the main effect, which is the effect of gold price inflation on boy mortality but we are still able to estimate the girl-boy differential in mortality, and it is significantly positive. The estimates are also robust to using a mother fixed effects specification and to varying the range of birth orders included in the sample. Since oil and gold prices are correlated (albeit with a lag), we control for monthly oil price shocks. So as to distinguish gold price effects from income effects, we also control for monthly rainfall shocks, and we include interactions of both oil price shocks and rainshocks with a girl dummy to allow for girl-boy differences in their impact on neonatal mortality. ${ }^{7}$ The estimated gold price effects are robust to these controls. This is important as it is only gold prices (and not oil prices or rainfall shocks) that are directly related to dowry costs. We assessed heterogeneity of the effects of gold price shocks on neonatal mortality with respect to household wealth. The effects are driven by households in the bottom $60 \%$ of the wealth distribution. As these households are less likely to hold stocks of gold they are less likely to experience wealth effects of gold price fluctuations. We discuss income and wealth effects of gold price shocks in more detail in Section 7.

Our finding that foetal and neonatal girl mortality rise with gold price inflation is consistent with previous evidence showing that Indian parents appear to start saving for dowry soon after the birth of a girl (Browning and Subramaniam (1995)). The underlying model is one in which families have static expectations. If gold prices follow a random walk, then the rational expectation is the static expectation (Deaton and Laroque (1992)). Using our time series sample we show that gold prices follow a random walk. A property of variables that

\footnotetext{
${ }^{7}$ Oil prices are an important component of the cost of living index and so positive oil price shocks reduce real income. Positive rain shocks in India have been shown to increase income, and are estimated to explain $45 \%$ of the variation in GDP. See Virmani (2006), Gadgil and Gadgil (2006), Nomoto (2016). Monthly GDP data for the 35 year period we analyse are unavailable but together oil price shocks and rainfall shocks allow us to control for income effects.
} 
follow a random walk is that the distribution of the variable exhibits a variance proportional to $t$ ( $t$ is time). If $t$ is around twenty years (the median age at marriage in India is 22), this variance can be quite large. If parents are risk averse, their behaviour will be determined not just by the expected value of gold prices, but also by their variance. ${ }^{8}$

If parents are loss averse (see, for instance, Karle et al. 2015), they will respond more to positive shocks that raise dowry costs than to negative shocks that lower dowry costs. And this is what we find. Again consistent with behavioural priors, we find that responses are larger for larger shocks, and larger when gold prices have shown a sustained rise in the preceding months. They are also significantly larger in the Northern states which have a long-standing tradition of son preference, and absent in the Southern states. Similarly, the main results are for Hindus and we demonstrate that they do not hold for non-Hindus (who are predominantly Muslims and Christians). We explain below why we focus on neonatal mortality and expect larger responses there. However, we investigated mortality in the post-neonatal period of infancy, and found a similar pattern of results.

Our paper contributes to the literature on dowry (Rao (1993), Bloch and Rao (2002), Anderson (2003), Anderson (2007), Sekhri and Storeygard (2014), Anukriti et al. (2017), Chiplunkar and Weaver (2017)) as well as to a larger literature on India's 'missing girls' (Sen (1992), Sen (2003), Bhalotra and Cochrane (2010), Anderson and Ray (2010)). We also contribute to a recent literature underlining the relevance of marriage-related customs for women's outcomes in developing countries (Ashraf et al. (2016), Borker et al. (2017), Corno et al. (2017), Lowes and Nunn (2017)). Our finding that dowry costs lead to foetal and neonatal mortality among girls in India is the first evidence of a causal relationship between dowry costs and son-preferring behaviours in India.

The rest of the paper is organized as follows. We describe relevant contextual material on dowry and son preference in India in Section 2. Section 3 describes the data and descriptive statistics. Section 4 discusses the link between dowry costs and gold prices, and presents evidence that dowry costs rise with gold prices. The empirical strategy is presented in Section 5 and the results are described in Section 6. Section 7 provides a discussion of the findings, putting the dowry costs interpretation of the documented effects of gold price inflation to the test. Section 8 concludes.

\footnotetext{
${ }^{8}$ We are grateful to Mukesh Eswaran for this observation.
} 


\section{Background}

\subsection{Dowry - Theoretical and historical perspectives}

In his seminal work, Becker (1981) modelled dowry and brideprice as monetary transfers that act to clear the marriage market (also see Rao (1993), Bhaskar (2015)). Discussing the limitations of the Beckerian approach, Botticini and Siow (2003) model the emergence of dowry as a pre-mortem bequest to daughters alongside post-mortem inheritance rights of sons as incentivizing the effort of sons on family property. Their model suggests that the withering of the institution across most of the world can be explained by the decline of agriculture, rising human capital and intergenerational occupational mobility (also see Boserup (1970)). However, dowry has persisted in India despite sustained economic growth since the 1990s and a strong trend in women's education and despite the 1961 Dowry Prohibition Act. Borker et al. (2017) suggest that dowry persists in India because of patrilocality norms including that staying single is not an option for girls while it is for boys.

Dowry in India originated in the Hindu community (Botticini and Siow (2003), Gupta (2002)). The non-Hindu group is dominated by Muslims, who have historically had brideprice and, although dowry has seeped into the practices of Muslim and other religious groups in India (Srinivas (1984), Waheed (2009)), the tradition remains stronger among Hindus (Borooah and Iyer (2004), Bloch et al. (2004)). Moreover, Muslims and Christians do not tend to manipulate the sex composition of their births through selective mortality, but instead, through continued fertility. ${ }^{9}$ For these reasons, we restrict the analysis to the Hindu population, which constitutes about $85 \%$ of all Indians.

Dowry has been in the news for instigating dowry deaths among married women in connection with the groom and his family attempting to extort higher dowry payments, and dowry deaths are likely to be the tip of an iceberg of domestic violence against women (Rocca et al. (2009), Bloch and Rao (2002)), the prevalence of which is estimated at 39 percent (Kishor and Gupta (2009)). ${ }^{10}$ However, empirical research on dowry is scarce in general (though see Bloch and Rao (2002), Sekhri and Storeygard (2014)) and, in particular there appears to be no work dedicated to analysing impacts of the institution on son preferring behaviours. ${ }^{11}$

\footnotetext{
${ }^{9}$ See, for instance, Bhalotra et al. (2010) who show that Muslims have better child survival rates in India conditional upon relevant covariates, and smaller gender gaps in child survival, Bhalotra and Cochrane (2010) who show that Hindus do and Muslims do not conduct female foeticide, and Almond et al. (2013) who document this difference in behaviour between Indian (mostly Hindu) and Pakistani (mostly Muslim) immigrants in Canada.

${ }^{10}$ See, for instance, a 2014 news item at http://www.bbc.co.uk/news/world-asia-india-29127425

${ }^{11} \mathrm{~A}$ recent review states that "evidence on the impacts of the dowry system on womens welfare is mostly anecdotal" (Jayachandran (2014)). In its 426 pages, the World Development Report on Gender (The World
} 


\subsection{Son Preference - Mechanisms}

A vast literature documents the various ways in which Indian (and, in particular, Hindu) families exercise their preference for sons, for instance, through differential fertility stopping (Bhalotra and van Soest (2008)), female foeticide (Jha et al. (2006), Bhalotra and Cochrane (2010)), and gender-differentiated parental investments in antenatal care, breastfeeding, nutrition and immunization (Bharadwaj and Lakdawala (2013), Chakravarty (2010), Jayachandran and Kuziemko (2011), Oster (2009)). This relative neglect of girls can lead to excess mortality, especially among very young children, because infectious disease is rife and young children are especially prone to contract infections with their nascent immune systems. Child mortality is therefore often used as a marker of parental investments. Insofar as other determinants of mortality do not discriminate between boys and girls or reverse patterns by favouring girls, the girl-boy mortality differential will tend to mirror gender differentiation in investments.

The phenomenon of India's missing girls appears to be getting worse in the last two decades despite strong economic growth (Kohli (2006)), fertility decline (Foster and Rosenzweig (2006), Bhalotra and van Soest (2008)), and narrowing gender gaps in education (Deolalikar (2007), The World Bank (2012)). One reason for the rising trend is that the introduction of prenatal sex detection technology has made it easier to manipulate the sex ratio. ${ }^{12}$ Families that conceive because they want a son but not a daughter can now detect the sex of the foetus and conduct sex-selective abortion. Street advertisements in India encourage families to seek sex-selective abortion to avoid dowry costs. For instance, Desai (1994) reports that abortion clinics in Mumbai had posters with slogans such as "Better pay Rs 500 now than Rs 50,000 later". The Rs 500 is the cost of abortion and the Rs 50,000 refers to the future cost of dowry. Even if the incentive to 'eliminate' girls were unchanged, the availability of ultrasound scanners and, alongside, cheap (and often unsafe) abortion clinics has lowered the (financial and pyschic) cost.

Bank (2012)) makes limited reference to dowry and, where it does, it only discusses whether increasing economic opportunities for women leads to lower dowry. It has a substantial discussion of missing girls but this discussion makes no reference to dowry.

${ }^{12}$ Bhalotra and Cochrane (2010) show that the timing of the first imports and, later, the licensing of local production of ultrasound scanners line up with a deviation of the sex ratio at birth from the normal range, in particular for second and higher order births in Hindu families with first-born daughters. These changes followed import liberalization and the deregulation of industrial licensing and were, as it happens, part and parcel of the process that fuelled India's transition into high growth. The authors estimate that as many as 0.48 million girls per annum were selectively aborted during 1995-2005, more than the number of girls born in the UK each year. The authors also show that female foeticide is more likely in wealthier families and families in which the woman is relatively well-educated, most likely because desired fertility is lower in these families. Wealthy, educated and high caste families also incur higher dowry costs. 
Consistent with this, Anukriti et al. (2015) show that, after the introduction of ultrasound, postnatal excess girl mortality declined sharply with the gender gap in neonatal mortality (and post-neonatal mortality) narrowing. This suggests a substitution of the decisive, purposive act of sex-selective abortion for postnatal neglect, which is a more indirect and hence more inconclusive way of manipulating the sex ratio of births. We shall split the time series sample into a pre and post-ultrasound period to investigate whether gold prices also motivated prenatal mortality in the post period.

\section{Data and Descriptive Statistics}

Individual data on neonatal mortality rates for births in the period 1972-2005 are extracted from the three rounds of the National Family Health Survey of India (NFHS) conducted in 1992-3, 1998-9, and 2005-06 (see Bhalotra et al. (2010) for details of the survey and the construction of the child mortality data). The survey interviews women aged 15-49 (13-49 in NFHS-1) to obtain complete fertility histories, including the dates of all live births and of any child deaths. The data provide information on relevant covariates including birth order, caste, religion, assets and education of parents. Data on international gold prices from the World Gold Council, as well as monthly oil price data are from the World Bank are merged into the birth file by birth month and year. All prices are deflated using the US consumer price index (CPI) because they are international prices in dollars. Monthly rainfall data are from the Palmer Drought Severity Index (PDSI) compiled by the National Center for Atmospheric Research (see Dai et al. (2004) for details). The PDSI records the amount of rainfall within areas sectioned as 2.5 degrees in longitude and 2.5 degrees in latitude. We constructed month and state averages of the PDSI and merged them with the individual mortality data by month and state. Table 1 provides summary statistics of the main outcome variables as well as gold prices. Our baseline sample is limited to children of second birth order, since families that move to higher order births may be different in unobservable ways from families that do not. ${ }^{13}$

Neonatal mortality and the sex ratio at birth: The average neonatal mortality rate in the sample is $4.64 \%$. This rate is higher for boys $(5.05 \%)$ than for girls $(4.20 \%)$, in line with a literature that documents the biological disadvantage of boys relative to girls in the first months of life (e.g. Waldron (1983)). The share of girls among births averaged over the entire period is 0.479 , and previous work cited earlier shows that this exhibits a strong trend through our sample period, deviating from the normal sex ratio at birth after 1985 (Bhalotra and Cochrane (2010)).

\footnotetext{
${ }^{13}$ This is further discussed in Section 5 .
} 
Gold Prices: Figure 1a shows the deflated monthly time series of gold prices during 1972-2005 in logarithms. There is considerable monthly variation, which we exploit in the analysis. Figure 1b plots the growth rate of monthly log gold price between 1972-2005. The figure demonstrates that changes in monthly gold prices in the international market exhibit a lot of variation and this variation seems to follow a random walk. If gold prices (like many commodity prices, (Deaton and Laroque (1992))) follow a random walk, then the first difference of the price will be white noise (random). We tested the time series properties of gold prices for the samples we analyse and, for greater confidence in our findings, we implemented two tests, varying the null. The results, reported in Appendix A.1, show that we cannot reject that gold prices follow a random walk.

Table 1 shows that mean of the change in the logarithm of gold prices is close to zero and the standard deviation is $4.5 \%$ during 1972-2005, smaller in the post-1985 (2.6\%) than in the pre-1985 sample (6.3\%). This is probably on account of sharp changes in gold prices at the end of 1979. In January 1980 gold hit a record price of 850 US dollars per ounce. Adjusting for inflation the 1980 record high price was $\$ 2,079$ an ounce at 2006 prices. After reaching those dizzy heights it then plummeted down and remained steady in the 300-400 dollar range for some years before starting to climb again to higher levels. In the Results section, we examine variation around this large shock, and also show that the main time series results are robust to excluding this period from the analysis.

\section{Dowry and gold}

It is estimated that 70 to 90 percent of households in India give dowry in marriage and that close to 95 percent of those who give dowry report giving gold. ${ }^{14}$ That gold is integral to dowry is also evident in media coverage (Srivastava (2012), Jadhav (2015)) and in the academic literature (Rao (1993), Srinivasan (2005), Jejeebhoy and Sathar (2001)).

Jewellery constitutes a large share of India's aggregate gold demand, and although this share declined from $97 \%$ during the 1980 s to $84.5 \%$ during the 1990 s and $78 \%$ during $2000-05$, it remains high (Kannan and Sarat (2008), Munshi (2011)). Aggregate gold consumption in India grew at a trend rate of $10.5 \%$ during 1980-2005, more than twice the rate of growth of global gold demand, at $4.5 \%$. There is anecdotal evidence that dowry includes not only gold but also silver jewellery and so one might imagine that when gold prices increase, people switch to silver jewellery. However the price of silver tracks the price of gold closely (see Figure A.1) so silver prices are unlikely to act as an omitted variable.

\footnotetext{
${ }^{14}$ See the Survey of the Status of Women and Fertility (SWAF) 1993-94 (Smith et al. (2000)) and also data from the Human Development Profile of India 1994 (Desai et al. (2007)) and The World Gold Council report (World Gold Council (2002)).
} 
Our hypothesis is that an unexpected gold price rise magnifies excess female mortality because parents perceive it as raising the financial burden of dowry. While the descriptive evidence above establishes that dowry contains gold, we could find no systematic evidence of the gold price elasticity of dowry value. We therefore estimate this, modelling the value of dowry payments made in the year of marriage $t$ for daughter $i$ as a function of gold prices in her year of marriage. We use the 1999 wave of the Rural Economic and Demographic Survey (REDS) to obtain information on the monetary value of dowry payments. ${ }^{15}$ The estimated equation is

$$
d_{i t}=\alpha+\beta \cdot \ln P_{t}+\delta^{\prime} X_{i}+\eta^{\prime} Z_{t}+t+t^{2}+\varepsilon_{i t b}
$$

where $d_{i t}$ is the logarithm of dowry value paid by bride $i$ 's family in year $t, \ln P_{t}$ is the logarithm of the real gold price during the marriage year, and we control for relevant couple characteristics $X_{i}$ including caste and education of the bride and the groom, number and gender composition of the bride's siblings, and time trends. We also introduce time-series controls $Z_{t}$ including rainfall shocks, state GDP, oil and rice price shocks.

We find a robust positive relationship between gold prices and the value of dowry payments (see Table 2). First, this validates gold prices as a marker of the financial burden of dowry. Second, the point estimate of the elasticity is around 0.8 , and we fail to reject that the elasticity is lower than unity in all of the specifications in Table 2). ${ }^{16}$ We might have held a prior that the content (quantity or composition) of dowry would adjust to gold prices so as to maintain dowry value- but if this were the case, then dowry value would not respond to gold prices as any change in prices would be offset by changes in gold quantities in dowry. Our results allow us to reject full adjustment, consistent with sticky social norms regarding content. The result confirms a premise of our study which is that gold price changes map into dowry burden. ${ }^{17}$

\footnotetext{
${ }^{15}$ These are reported by the household head for all daughters, along with the year of marriage. The year of marriage for the daughters who marry in these data ranges between 1969 and 1999 and their year of birth from 1944 to 1997. Dowry values refer to values at time of marriage and we deflate them using the Indian CPI from the World Bank Development Indicators.

${ }^{16}$ We only ever observe the dowry value of realized marriages and that the true effect on expected dowry is likely to be greater, as some families may delay marriage in response to a gold price rise.

${ }^{17}$ Although we are focused upon the marginal effect of gold inflation, it is relevant to describe the underlying trends. Previous research has argued that India is witnessing dowry inflation (Rao (1993), Anderson (2007)), that aggregate gold demand in India is rising and that gold remains an integral part of dowry (section 2). However anecdotal evidence suggests a tendency for consumer goods such as washing machines and refrigerators to be included in dowry since the 1990s when India's trade liberalization improved access to these goods for a large fraction of the population. Our estimates however show no evidence that the relevance of gold prices to dowry has diminished over time. In fact we re-estimated the regressions of dowry value on gold prices dividing the sample of marriage years at 1990 and we found a larger elasticity of dowry value w.r.t. gold prices after 1990; results available upon request.
} 


\section{Empirical Strategy}

The hypothesis we wish to test is that unexpected increases in gold prices intensify an aversion to having daughters measured by the ratio of surviving boys to girls, a commonly used indicator in the son preference literature (Sen (1992), Almond and Edlund (2008)). The mechanism we propose is that higher gold prices are perceived as an increase in the cost of dowry, which raises the cost of having daughters in absolute terms and relative to sons (who will bring in dowry). This need not imply that parents attach greater weight to the welfare of sons, only that dowry raises the cost of having daughters. A simple framework that captures this idea is sketched in Appendix B.

We analyze gold price changes using time series data on 420 months in the period 19722005. We test whether quasi-random changes in gold prices generate changes in parental demand for girls vs boys by estimating:

$$
y_{i t m s}=\alpha+\beta \cdot \Delta l n P_{t m}+\lambda \cdot \Delta l n P_{t m} \cdot f_{i}+\eta^{\prime}\left(Z_{t m} \cdot f_{i}\right)+\gamma^{\prime} X_{i t m s}+\theta_{t}+\kappa_{m}+\theta_{s}+\varepsilon_{i t}
$$

where $y_{i t m}$ is the outcome of interest for individual $i$ born in month $m$ in year $t$ in state $s$. Outcome $y$ is, initially, an indicator for neonatal mortality; later, we estimate similar equations for the probability that a birth is a girl rather than a boy, and adult height in centimeters. $\Delta \ln P_{t m}$ is the difference in the logarithm of the real gold price in the month and year of birth $t m$ relative to the previous month, and $f$ indicates a female child. ${ }^{18}$ Standard errors are clustered by the month of birth $t$.

Neonatal Mortality The marginal effect of gold price shocks on boy neonatal mortality risk is given by $\beta$, and the differential effect on girl relative to boy mortality is given by $\lambda$. The vectors $\theta_{t}$ and $\kappa_{m}$ denote year and month of birth fixed effects respectively. Birth year fixed effects will flexibly pick up any nationwide shocks that might influence mortality risk. Month fixed effects control flexibly for seasonal variation (Doblhammer and Vaupel (2001)).

The identifying assumption (which we have tested; see Section 3) is that monthly gold price shocks are idiosyncratic. Nevertheless, in a very harsh test of our hypothesis, we control for month $\times$ year of birth fixed effects. While these are collinear with the monthly deviations in the gold price, their differential impact on girl mortality is still identified, and this specification by construction eliminates all possible omitted trends. Another test

\footnotetext{
${ }^{18}$ If, instead, we use the Hodrick-Prescott filter to extract the cyclical component of gold price variation from the trend and use this as the price shock measure, the results are similar (and available on request). In a further robustness check, we estimate a version of model 2 on data collapsed to the month (and state of birth and gender) level, so that we can define the dependent variable in differences: $\Delta y_{t m s}$ which is the difference in neonatal mortality rates of children of a given gender born in state $s$ in month $t$. These results are provided in Appendix Table A.6.
} 
we present of omitted trends is in the nature of a placebo test, including leads of gold prices. Since future variables cannot cause current outcomes, if the leads were statistically significant, this would indicate a mis-specification.

$X_{i t m}$ contains the main effect for female child $f_{i}$, indicators for the state of residence, upper vs lower caste of the household, child birth order and the sex of the eldest sibling of the index child. We also include time-series controls, $Z_{t m}$ to capture income changes. Monthly GDP data through 1972-2005 are unavailable for India. However, we control for income effects using monthly world oil prices and monthly deviations of rainfall from historical state-level means in the birth month, interacting both of these with with gender of the child so as to test for the possibility that the gender-differentiated gold price effects we document stem from income shocks.

Since families that move to higher order births may be different in unobservable ways from families that do not, we restrict the sample to second births. We do not include first births because of evidence that families desire one girl but not more, and there is no discernible sex selection at first birth so that the sex of first births is quasi-random (Bhalotra and Cochrane (2010), Rosenblum (2013)). ${ }^{19}$ We also investigate a specification in which we use higher order births and control for mother fixed effects. This controls for unobserved heterogeneity to the extent that this is fixed over time, for example, it will control for time-invariant differences in son preference or desired fertility across families. This allows for endogenous differences in compliance, for example, that mothers (or families) who react to gold prices are more likely to seek information on gold prices. $^{20}$

\subsection{Neonatal Mortality: Heterogeneity}

We start by discussing three specifications designed to illuminate better the way in which parents form expectations, and react. We then discuss heterogeneity by population group.

First, we jointly investigate asymmetry and heterogeneity by the size of the shock. Our hypothesis is that parents will react more to larger shocks and, if they are loss averse, that excess neonatal mortality among girls will react more to price rises than to price falls. We created indicators for quintiles of the distribution of price changes, using absolute values. We labeled the bottom quintile small, the top quintile large, and the three middle quintiles

\footnotetext{
${ }^{19}$ In the pooled NFHS sample only 5.5 percent of women over 35 had just one child, so there is limited selectivity in proceeding to a second birth. In fact since we use monthly data and endogenous fertility choices can only be realized with a nine month lag, our concern is not that of endogenous heterogeneity in fertility, i.e. fertility responding to gold prices, but rather to selectivity in the sample of higher order births on unobservables such as son preference or desired fertility.

${ }^{20}$ Since we do not include first births in the estimation sample, the sample for the mother fixed effects estimation is the sample of women with at least three births. As this is a select sample, we first present estimates without mother fixed effects on this sample, and then estimates with mother fixed effects so that the separate roles played by sample restrictions and by the addition of mother fixed effects are delineated.
} 
medium sized shocks. We created an indicator for whether the price shock was positive or not. We then interacted the indicators for size of shock and direction of shock and included these as independent variables in the model.

Second, we tested whether a price rise in any given month has a larger impact on neonatal mortality in months preceded by a period of rising prices. To do this, we created an indicator that is 1 if the average price change in the last $n$ months was positive, and 0 otherwise, and we interacted this with an indicator for positive price shock in the month of birth. We conduct this exercise for $n=1,2,3,6$ and 9 months. Finding that the relationship of interest is stronger when gold price changes are sustained over a period of time would also mitigate any potential concern that our results are driven by mean-reverting price shocks. ${ }^{21}$

Third, we estimate a specification that allows neonatal mortality to depend not only on a gold price shock in the birth month but, alternatively, on gold price shocks averaged over longer periods starting before birth and ending in the birth month. ${ }^{22}$ We re-define the independent variable to capture gold price shocks as the log average price over the $\mathrm{n}$ months ending in the birth month minus the log average price in the $\mathrm{n}$ months preceding that, allowing $\mathrm{n}=1,3,6$ and 12 months. The hypothesis is that parents may be more responsive when price shocks are sustained over a period longer than a month.

A vast literature has documented that son preference in India is stronger in the North than in the South of the country (see for example, Miller (1981), Dyson and Moore (1983), Sen (2003)). We therefore estimate the main equations for two sub-samples that include the most discriminating Northern states vs the four Southern states. Similarly, as discussed in Section 2, Hindus are more likely than Muslims and Christians to manipulate the sexcomposition of their births. While the main results are for the Hindu sample, we also show results for the non-Hindu sample in the spirit of a placebo test. Finally, we study differences in responses by an index of household wealth.

\footnotetext{
${ }^{21}$ We do not expect mean reversion in the outcome. In general, if a shock at $t$ results in a jump in mortality then, assuming that the most fragile die, the surviving population at $t+1$ is healthier and this generates a potential problem of endogenous selection or compositional change. A common procedure for addressing this is to include the lagged dependent variable on the right hand side. However the neonatal mortality outcome is fully resolved in a month- the child either survives or does not survive the birth month (as a function of a price shock in that month). In the next month, a new birth cohort is born. Nevertheless, Appendix Table A.6, where an indicator for individual neonatal mortality is replaced with the change in the month-averaged neonatal mortality rate addresses this concern.

${ }^{22}$ This specification is more general than the preceding one, as it allows for sustained price rises as well as sustained price falls, and because it accounts for the actual magnitude of recent gold price changes whereas the previous model used an indicator for positive price rises being sustained or not.
} 


\subsection{Postneonatal Mortality}

We extended the analysis to study mortality at different stages of infancy, after the birth month. Specifically, we estimated how mortality of boys relative to girls at age t responds to gold price shocks defined as the difference in the log average price between birth and age $\mathrm{t}$ relative to the log average price in the preceding t months. We define $t$ as 1, 2, 3,6 and 12 months. We present these results to fill out the picture. We capitulate below reasons that lead us to expect larger responses in the neonatal period. ${ }^{23}$

The first is biological. The hazard of death declines exponentially from birth to age five, after which it flattens. In other words, mortality risk is higher in the neonatal period than at any other stage of life, and also significantly higher than in the post-neonatal infant months. This is because babies are more likely to contract infection and have nascent immune systems. In addition, they are more vulnerable to neglect because the high velocity of growth in this period translates to high nutritional (resource) requirements. The second pertains to parental behaviours. Birth is a major event. In the pre-ultrasound period to which our results for neonatal mortality pertain, the gender of the birth is a shock that is revealed to parents in the birth month, and it seems plausible that they react immediately. In support of this argument, (Browning and Subramaniam, 1995) found, using Indian consumption survey data, that the birth of a girl rather than a boy was associated with an increase in household savings. They had no data on dowry but rationalized this by arguing that parents start saving for the dowry of their daughters as soon as they are born. A third factor is that the psychic costs of neglect and death are likely to be smaller, the younger the child, as investment and attachment accumulate as the child grows older. So in the pre-ultrasound era, neonatal death was probably preferred to death at later ages. The fact that parents have substituted sex-selective abortion for post-natal neglect of girls (Anukriti et al. (2017)) is consistent with this argument. Our analysis of sex-selective abortion shows that parents do consciously eliminate girls. However, we expect that neonatal mortality arises not so much by killing newborn girls but, rather, from neglect. It is then pertinent that the risk of dying from infectious disease, low nutrition or adverse prenatal conditions is larger in the neonatal period than at any other stage of life.

Sex-Selective Abortion We introduce the sex ratio at birth as a new dependent variable, with the expectation that gold prices modify the sex ratio at birth post-1985 and not before since there was no widespread availability of prenatal sex detection before 1985 (see Section 2). Indeed, the pre-1985 sample provides a placebo test. If parents switch from

\footnotetext{
${ }^{23} \mathrm{We}$ also observe that there is considerable monthly variation in the gold price time series data (see Figures $1 \mathrm{a}$ and $1 \mathrm{~b}$ ), which we are able to exploit by matching it to the birth month.
} 
eliminating girls in the neonatal period to eliminating them in the foetal period, then we may expect that gold prices are mirrored in girl (relative to boy) neonatal mortality pre-1985 and in the sex ratio at birth post-1985. Male-biased sex ratios at birth are a marker of female foeticide (Almond et al. (2013); Bhalotra and Cochrane (2010)). We therefore present results for these two outcomes splitting the sample at 1985

When the outcome is the sex ratio at birth, the girl-boy differential is implicit i.e. it is incorporated in the dependent variable, and so the independent variable of interest is simply $\Delta \ln P_{t m}$ - there is no explicit interaction with a girl child indicator. As a result, this specification cannot accommodate month $\times$ year of birth fixed effects. While for neonatal mortality (death in the birth month) the main specification models impacts of price shocks in the birth month, for the sex ratio at birth we model impacts of price shocks in each trimester of pregnancy.

Height at Maturity The models of neonatal mortality and the sex ratio at birth both capture immediate responses of parents to gold price shocks. These responses may involve under-investment in the nutrition or immunization of girls (that elevates the risk of neonatal mortality), or the purposive acts of prenatal sex detection and girl abortion.

To the extent that the mechanism is under-investment in girls, although some will succumb, some will survive. Among survivors, we expect that early-life neglect leads to a permanent decrement in stature stemming, it is thought, from an increased burden of infections and inflammation (Bozzoli et al. (2009), Akresh et al. (2012)). Ideally, we would like to test for effects on investments in child health (e.g. breastfeeding), but this information was only collected for children born in recent years ( 5 years before the survey date), which implies that we can not look at investments as a function of gold prices in the long time series. In particular, we cannot analyze the effect pre-1985 (before the availability of prenatal sex diagnostics), since the first wave of NFHS was conducted in 1992-93. Therefore, we use height as a proxy for childhood nutrition and other health inputs.

We therefore also study height at maturity as a marker of parental investments, the mechanism at play in generating the marginal effects of gold prices on neonatal mortality. When we model height, for consistency with the models for neonatal mortality and birth sex ratios, we report impacts of gold price changes in the birth month. However since we focus upon survivors, and parents may continue neglect beyond the birth month, through infancy (when the risk of death from under-investment remains high), we also show results for height using gold price shocks averaged over the birth year. 


\section{Results}

\subsection{Neonatal Mortality}

We present estimates for mortality (and, later, the birth sex ratio) for the entire period and for each of the pre and the post-ultrasound periods. Estimates of equation 2 for neonatal mortality are in Table 3. We find that gold price shocks are associated with an increase in the neonatal mortality risk of girls, which is statistically significantly different from the response for boys. In fact we see a decrease in the neonatal mortality risk of boys.

Since sons bring in dowry at marriage, gold price increases may raise the demand for sons. Our finding that boy mortality tends to decline is consistent with this. However it seems plausible that parents are loss averse and react more to the prospect of having to pay dowry than to the prospect of receiving dowry. Also, a girl's parents in India are entirely responsible for providing dowry whereas when their sons bring in dowry, parents may only appropriate a share of it from their sons (Anderson and Bidner (2015)). So in fact all we require is that the coefficient for boys is non-positive and that the marginal effect of gold inflation on girls is significantly different (more positive) from the marginal effect on boys. Both of these conditions hold.

Overall, the results are consistent with our hypothesis that gold price shocks, by raising the cost of dowry and hence the perceived cost of having daughters, lead parents to want fewer daughters and this shows as an increase in girl neonatal mortality.

Results for the Period Pre vs Post Ultrasound: Splitting the sample, it is clear that the divergence of mortality risk between boys and girls created by gold price shocks comes entirely from pre-1985 birth cohorts. Notice that the effect of gold price shocks on boy mortality is very similar pre and post-1985 but the differential impact on girls (the coefficient on the interaction term between the shock and a dummy for girl gender) is a lot larger and only significant for pre-1985 cohorts. $^{24}$

In the post-1985 period, when prenatal sex detection becomes feasible, parents who do not want a girl who survives to marriage age have two choices. Either they can abort the unwanted girl foetus, or they can reduce prenatal investments in response to the knowledge that the foetus is a girl. If they take the second approach then the neonatal mortality of girls will tend to increase, as in Bharadwaj and Lakdawala (2013). However, post-1985, we find that girl neonatal mortality does not respond to gold prices, so this channel is not discernible. In the next section, we demonstrate that the first channel is.

\footnotetext{
${ }^{24}$ The lower panel of Table 3 presents estimates of marginal effects for girls with standard errors. These are large positive numbers that border on significance pre-1985. Once we use the entire time series sample and an interaction with a post-1985 indicator instead of implementing a sample split, these marginal effects become statistically significant (see columns 10 and 11).
} 
Consider effect size using the estimates in column 11, showing a marginal effect of 4.28 for pre-1985 girl births. A one standard deviation increase in the change in log gold prices (6.3 percent) leads to a significant 0.27 percentage point increase in the neonatal mortality risk of girls. The same shock is estimated to reduce boy neonatal mortality by 0.23 percentage points but this coefficient is not precisely estimated at conventional levels.

Sensitivity to Time-Varying Controls: Our finding that unexpected gold price inflation leads to absolute and relative increases in girl mortality is conditional upon controls for month, year and state fixed effects, individual controls listed earlier and to rainfall shocks and oil price shocks interacted with the girl child indicator. It is also robust to controls for month $\times$ year of birth fixed effects. The possibility that omitted variables drive our results is further undermined by our finding that gold prices move boy and girl mortality in opposite directions, at least insofar as the omitted variables are such that they move boy and girl mortality in the same direction. We also implemented a placebo test checking if future prices predict neonatal mortality of individual $i$ born in month $t$; see Appendix Table A.8. There is no indication that changes in gold prices in the months following a child's birth month predict whether s/he survived the first month of life.

Mother Fixed Effects: A specification that incorporates mother fixed effects is in Table 4, see columns 4-6. ${ }^{25}$ The marginal effect on girls is almost identical to that in Table 4, the estimated coefficient is 4.49 compared with 4.276 in Table 3 . The marginal effect for boys is now much closer to zero. ${ }^{26}$

Excluding the Outlier: As discussed in Section 3, there was a historic spike in gold prices in December 1979. Appendix Figures A.2a and A.2b show event study plots using a window of seven months on each side of the shock. In line with the main results, we see that this episode led to an increase in girl mortality alongside no change in boy mortality. To be sure that the results for the longer time series are not driven by this spike, we reestimated the equation excluding from the sample children born between 1 November 1979 and 1 February 1980 when gold prices climbed to a peak. The estimated effect of gold prices on girl mortality is similar and not statistically significantly different, see Table A.11.

\footnotetext{
${ }^{25}$ As discussed earlier, we need at least two births per mother and since we do not include first births as subjects, we need at least three. So as to increase statistical power we now include not only second but also higher order births. In columns 1-3 we present results on this sample but without controlling for mother fixed effects.

${ }^{26}$ The standard errors are large enough that the marginal effect for boys is not significantly different than it was in Table 3. However one might want to consider why the coefficient is no longer negative. Recall that the samples are different, so one rationalization of this change is that second born boys benefit from gold prices but third and higher order boys do not and as these higher order births are now in the sample, the average effect is smaller. We do not speculate further since the boy coefficient is consistently imprecisely estimated. Also our hypothesis is focused on girl mortality.
} 
Heterogeneity by Population Group: The evidence would be more compelling if we could demonstrate that population sub-groups which we expect will exhibit weaker responses to changes in expected dowry cost do so. Also, lurking concerns about omitted variables would be undermined by sub-group heterogeneity in the coefficients unless there were reason to expect that the omitted variables exhibit the same variation across sub-groups as the outcomes of interest.

We estimated equation 2 for non-Hindu families in the spirit of a placebo, given evidence that non-Hindus in India do not have the long-standing dowry tradition that Hindus have (and evidence that they exhibit less son preference evidenced by lower rates of excess girl mortality (Bhalotra et al., 2010) and less male-biased sex ratios (Bhalotra and Cochrane, 2010). See Table A.9. The marginal effect of the gold price hike on excess girl mortality emerges entirely from the Hindu sample.

We also estimated the equation for two subsamples of states, the Northern BIMARU states (Bihar, Jharkhand, Madhya Pradesh, Chhattisgarh, Rajasthan and Uttar Pradesh) and the Southern states (Andhra Pradesh, Telangana, Karnataka, Kerala and Tamil Nadu), the former having a historically stronger tendency to practice postnatal gender discrimination. The results are in Table A.5. The gender-differentiated neonatal mortality response to gold price shocks that we have observed on the national data is absent in the South and larger (in terms of point estimates) in the North (lack of statistical significance is likely due to the smaller sample size as we restrict the Northern states).

Results by household wealth are discussed in Section 7. Essentially, we find that the average results emerge from the poorer households in the bottom three quintiles, see Table A.12. In fact the effect of gold prices on girl mortality is similar for wealthy and poorer households but, for boys the response to gold prices emerges from poorer households. We argue in Section 7 that this undermines a potential competing hypothesis that our findings reflect wealth increases among households that store gold as wealth, rather than dowry cost increasing effects of gold price increases.

Heterogeneity by Measure of Price Behaviour: So as to examine our priors on the plausibility of birth-month price shocks drawing responses from parents, we estimated heterogeneity in responses by the size of the price shock, its direction, and whether or not price changes were sustained over a longer period.

First, we jointly test whether household responses are increasing in the size of the shock, and whether they are symmetric for price rises vs price falls. See Table A.2. We find that neonatal mortality responses are increasing in the size of the shock and that they are asymmetric in a manner that is consistent with loss aversion. It seems that girl mortality is primarily influenced by price increases, while boy mortality is primarily influenced by price 
falls. This pattern is consistent with loss aversion because parents of girls give dowry and parents of boys receive dowry. When gold prices fall (and expectations of outgoing dowry commitments fall), there is no significant impact on girl mortality. When gold prices rise (and expectations of incoming dowry rise), there is a decrease in boy mortality. Among previous evidence on loss aversion, Karle et al., 2015 show that behavioural choices (purchase decisions) of agents with rational expectations are influenced by expectation-based loss aversion about prices when prices are uncertain and preferences (tastes) are given.

Large gold price increases (defined as shocks in the top quintile of the distribution of price shocks, using absolute values) are associated with an increase in female neonatal mortality 1.85-1.92 percentage points larger than small price increases (defined as changes in the bottom quintile), and the difference is statistically significant - see the marginal effects reported in the bottom panel in columns (4) and (5) (for the pre-ultrasound period 1972-85, which is where we expect impacts on neonatal mortality). Similarly, medium sized price shocks (defined as the middle three quintiles) increase girl mortality by 1.37 to 1.41 percentage points more than small shocks, although this difference is imprecisely estimated.

Second, we tested whether positive price shocks in any given month have a larger impact on neonatal mortality in months preceded by a period of rising prices, as it seems plausible that parents respond to a shock if they have seen sustained increases. See Figure 2. We find that this is the case, and the difference is statistically significant for retrospective periods of 3 and 6 months. However, in every case, the magnitudes are clearly different, it is just that for windows of 1, 2, 4 and 9 months, the confidence intervals are large. This result is consistent with a likely form of expectations formation. In addition, it mitigates any potential concern that our results are driven by mean-reverting price shocks.

In an alternative but related specification we allow neonatal mortality to depend not only on a gold price shock in the birth month but, instead, on gold price shocks averaged over longer periods (ranging from 3 to 12 months) before birth and ending in the birth month. See Table A.4. ${ }^{27}$ The marginal effect for girls is positive. The marginal effects obtained for different durations of recent price changes are not significantly different from another. While we may expect that parental responses are larger for price changes sustained for longer, this tendency may be offset by recent shocks having more salience or it may be that we do not have the power to detect significant differences. However, it is notable that the marginal

\footnotetext{
${ }^{27}$ This specification serves a broadly similar purpose to the previous. However it is more general than the previous as it allows for sustained price rises as well as sustained price falls. Also it accounts for the actual magnitude of recent gold price changes whereas the previous model used an indicator for sustained (and positive) price rises.
} 
effect is more precisely determined for cases where the growth (or fall) in average prices is taken over the longer periods of 6 or 12 months. ${ }^{28}$.

Postneonatal Survival: As discussed, we focus on neonatal mortality as this is where we expect the largest responses but we also investigate how price shocks alter survival rates in the post-neonatal period. See Table A.3. We find that price shocks that occur between the birth month and month $\mathrm{n}$ of life (n varies from 3 to 9 months) lower the chance of survival to age $\mathrm{n}$ for girls relative to boys. The marginal effect for neonatal mortality flowing from gold price shocks in the birth month is between 3.1 and 3.4 (depending on whether or not time-series controls are included), replicating the main result in Table 3. The new estimates are in columns 4-12. Columns 10-12, for example, show how mortality by the 6th month (i.e. mortality that occurs anywhere between birth and 6 months of life) responds to gold price shocks averaged over the first 6 months of life. The marginal effect is 1.6 and 2.2. ${ }^{29}$

\subsection{Prenatal Survival}

The results in the preceding section showed that neonatal mortality of girls rises after an unexpected increase in gold prices in the birth month and that this is most clear among cohorts born before the introduction of prenatal sex detection technologies i.e. before 1985 (see section 2). So either preferences changed after 1985 or the way in which they were expressed changed. We hypothesise that the expression changed, following the evidence in Anukriti et al. (2015) which shows that fetal sex-selection tended to substitute sex-selective postnatal mortality once fetal sex-selection became feasible. In this section we discuss impacts of gold price variation on the probability of a girl birth, a marker of gender differences in fetal mortality. Results are in Table 5. We find that gold inflation reduces the probability of a girl birth.

The coefficient is large, negative and statistically significant post-ultrasound and indistinguishable from zero pre-ultrasound. Since parents did not know fetal sex pre-1985, the pre-1985 results serve as a placebo check. These findings are consistent with abortion being less costly in financial and psychic terms than carrying a child to birth and letting her die

\footnotetext{
${ }^{28}$ Recall that in the baseline results shown in Table 3, the coefficients for the girl-boy difference in neonatal morality are significant, but the marginal effect for girls is only significant when we pool the samples and use a post-1985 indicator to distinguish the samples before and after prenatal sex detection availability- as in the last columns of Table 3. Here we use the pre-1985 sample as this is where the neonatal mortality effects are found. So the marginal effect for girls is not significant. However the magnitude remains stable across the columns and similar to its baseline value. We do not rely upon this as we can achieve statistical significance by pooling with the post-1985 period but we refer here to recent work making the case that we rely excessively upon conventional p-value thresholds (Amrhein and Greenland (2018)

${ }^{29}$ The differences in marginal effects by $\mathrm{n}$ are not statistically significant. Price shocks in the birth month may have greater salience, but price changes that are sustained over a longer period are more likely to influence expectations, and we do not know exactly how these factors balance out. However, as discussed above in section 5.2 , we do expect neonatal mortality to be more responsive than infant mortality.
} 
from neglect. The estimates in column 8 of Table 5 imply that, during 1986-2005, a 1 s.d. increase in gold price inflation (of 0.026 ) results in an approximately 0.29 percentage point decline in the probability that a girl rather than a boy is born. ${ }^{30}$

There is evidence for India that girl abortion is systematically higher in families that do not have a son (Bhalotra and Cochrane (2010), Rosenblum (2013)). As these studies also establish that the sex of first births is as good as random, this provides quasi-experimental variation in the propensity to exercise son preference. We therefore interacted the change in log gold prices with an indicator for whether the first born child is a girl. Results are presented in Panel B of Table 5. The same one s.d. change in log gold prices is associated with a statistically significant 0.62 percentage point decline in the probability that a birth is a girl in families with a first-born daughter, while the association is not statistically significant in families with a first-born son. The $0.62 \mathrm{ppt}$ decline is about one-fourth of the total decline in the proportion of female births in families with first-daughters after 1995 (and a larger share of the decline since 1985); see Table 2 of Bhalotra and Cochrane (2010).

Since we estimate a coefficient not significantly different from zero for families with a first born son and these are roughly half of all families (given that the sex of the first born is quasirandom), our estimates imply a 0.31 percentage point reduction in the overall probability of a (Hindu) girl birth. Given that the natural chances of a girl birth are close to half, this implies an additional 0.62 girl fetal deaths in 100 conceptions. So a crude estimate of the substitution of prenatal for postnatal mortality in response to gold price increases is that for every one neonatal girl death pre-1985, $2.30(0.62 / 0.27$, where 0.62 is the marginal effect on the birth sex ratio and 0.27 is the marginal effect on neonatal mortality) girl conceptions did not survive to birth in the post-1985 period. ${ }^{31}$ This is very close to the substitution

\footnotetext{
${ }^{30}$ We estimated a model that allows gold price shocks in each of the three trimesters of pregnancy to influence the sex ratio at birth, see Appendix Table A.14. Only shocks in the third trimester are statistically significant and so this is what we show in Table 5 . However, it is notable that the coefficients are not significantly different across trimesters and the coefficients are of broadly similar magnitude in the second and third trimester. If we instead use gold prices in the birth month, to parallel the specification for mortality, we find a statistically significant coefficient that is about two-thirds as large as the coefficient we report, consistent with the birth month being part of the third trimester. Since abortions are more likely in the second trimester, we rationalize the prominence of the third trimester exposure as reflecting prenatal neglect of the child in the womb rather than abortion. Daughters that die in early infancy as a result of prenatal neglect may be reported as stillbirths, or their births may simply never be reported as India has an incomplete births registration system (Rose (1999), Leidl (2005), George et al. (1992)). Second, as the third trimester is closer to the time of birth, information in this trimester may be more salient. It may for example, be more likely that parents who have not already sought prenatal sex detection are induced to find out the gender of the foetus following gold price shocks that happen late in pregnancy.

${ }^{31}$ Table 1 shows that the s.d. of $\Delta \ln P_{t m}$ is $2.6 \%$ after 1985 , smaller than $6.3 \%$ before 1985 . We have estimated the marginal effects for neonatal mortality plugging in the $6.3 \%$ figure, and the marginal effect for the sex ratio plugging in the $2.6 \%$ figure to account for the actual variation in the data. However a synthetic like for like comparison could be done using in both computations the standard deviation for the full sample, which is $4.5 \%$.
} 
parameter estimated using average post-ultrasound responses of sex ratios and childhood mortality in Anukriti et al. (2015). Overall, these back of the envelope calculations suggest that gold prices are having an increasingly detrimental impact on the share of surviving girls (since girl abortion is rising and, although there is some offset in lower neonatal mortality of girls after birth, it is less than complete).

Similar to the exploration done for neonatal mortality, we assess whether Hindu households behave differently from households of other religions (primarily Muslim and Christian) which have a weaker tradition of dowry. Results in Table A.10 shows that it is only Hindu households that commit prenatal sex-selection in response to gold prices, consistent with the hypothesized role of dowry in driving this response.

\subsection{Stature}

In this section, we investigate impacts of gold price shocks in the birth month and birth year on adult stature. We take all adults in NFHS rounds 2 and 3, who, at the date of survey, when height is measured (by trained surveyors) are age 15 to 50 (women) or 15 to 55 (men). The birth years of these individuals range from 1942 to 1991 . We restrict the sample to individuals born between 1972 and 1991 because the gold price data go back to 1970, and because these birth dates cohere with the preceding analysis of neonatal mortality and birth sex ratios. Within this sample, the observations consist predominantly of pre-1985 births (94\% of individuals in the sample were born before 1 January 1985). This is useful as it is pre-1985 that parents appeared to be practising neglect of girls which was evident in higher neonatal mortality of girls following unexpected increases in gold prices. By construction, the sample with data on height contains only those individuals who have survived to maturity. If survivors are positively selected then the estimates we show here will under-estimate the degree of under-investment in girls.

Results are in Table 6. Gold price inflation averaged through the birth year is associated with women, but not men, being shorter as adults. Using the estimates in column 5 and panel B, a one s.d. change in gold inflation in the birth year (which is 0.202 for annual gold price inflation) is estimated to result in women being 0.1 centimeter shorter. The estimated coefficient for men is negative but less than half the size of the coefficient for women. If we use gold prices in the birth month, we see positive coefficients for both men and women but again men do better than women: only the coefficient for men is statistically significant, indicating that men born in gold inflation months are taller, while the coefficient for women is small (about a ninth the size of the male coefficient) and indistinguishable from zero. These results are robust to the controls described for the survival equations. They are consistent 
with our hypothesis that increases in gold prices lead to parental investments favouring boys over girls. $^{32}$

Overall, perceived increases in the cost of having a daughter induced by gold inflation appear to lead to lower health investments in girls. Not only are there fewer surviving girls but the surviving girls are shorter. Infection and inflammation in infancy which tend to correlate with under-nutrition and under-immunization have been shown to result in decrements in adult height and this in turn has been linked to lower life expectancy, cognitive performance and socioeconomic status (Crimmins and Finch (2006); Thomas and Strauss (1997), Strauss and Thomas (2007), Waaler (1984), Fogel (2004)) and also to the health and survival of a woman's offspring (Bhalotra and Rawlings (2011)). Using the third round of the National Family Health Survey, we find that taller women are more educated, marry later, and are less likely to experience domestic violence. These associations (available on request) are not causal, but they suggest that the neglect of girls exposed to the gold price shock created a cluster of disadvantage in later life.

\section{Discussion}

In this section we discuss interpretation of our results. We have provided evidence that gold prices impact dowry value and, albeit on a different sample, that parents react to unexpected increases in gold prices by committing girl abortion or neglecting girls in the first month of life, when neglect more easily translates into death. Our contention is that this behaviour is a response to a perceived increase in the financial burden of dowry associated with daughters. But why do parents exercise these behaviours in response to gold price shocks at birth when dowry payments are made at the time of a daughter's marriage? As discussed above, as gold prices follow a random walk (like many commodity prices; (Deaton and Laroque, 1992)), then a change is an innovation, and the rational expectation at any time is the static expectation. Because gold prices follow a random walk, their variance increases with time and if parents are risk averse then the variance will matter in addition to the expected value of gold prices. In extensions of the main results, we show that responsiveness of neonatal mortality to price shocks in the birth month is increasing in the size of the

\footnotetext{
${ }^{32} \mathrm{~A}$ potential explanation for the difference in the birth month and birth year exposure results is that there are dynamics in the investment process. First, there will be some survival selection between the birth month and the birth year and, second, parents may make reinforcing or compensating investments in survivors as gold prices evolve and they receive new information. Since height is only fully determined after the adolescent growth spurt (Case and Paxson (2008), Moradi (2010), Beard and Blaser (2002)), there is more noise in these long run estimates than in the mortality and sex ratio estimates. Still, both the birth month and birth year exposure results show that gold price inflation in early life leads to a widening of the gender gap in height (which at the mean is as large, men being $164.7 \mathrm{~cm}$ and women $151.7 \mathrm{~cm}$ tall in India in our sample).
} 
shock, is asymmetric in a direction consistent with loss aversion and that it tends to be larger following a period of sustained growth in prices. ${ }^{33}$

In line with our findings, Browning and Subramaniam (1995) show that parents start saving for dowry as soon as they receive the unexpected information that their birth is a girl. They explain this in terms of consumption smoothing over the life-cycle. As they do not consider variation in dowry costs our purpose is distinct from theirs, but their results underline that parents are forward-looking and that parents of newborn girls are actively considering and accounting for the cost of dowry. That Indian families typically accumulate dowry over several years prior to the date of marriage is also documented in the World Gold Council Report (World Gold Council (2002)).

We interpret gold price variation as having the documented impacts on account of the association of gold prices with dowry. So as to challenge this interpretation, let us remove dowry from the picture. Suppose that gold is only purchased for its consumption value, for instance, as an ornament for parents, or as a means of storing wealth. Then an unexpected gold price increase will create a positive wealth effect among households that are net owners of gold. This will tend to increase investments in boys and girls and hence to reduce neonatal mortality of boys and girls. If there is son preference (parents attach more weight to the welfare of sons than daughters), then the reduction in mortality will be larger for boys. However we document an absolute increase in mortality of girls (rather than a smaller decrease). We also found reduced adult stature for girls born during the 1980 gold price hike, consistent with an absolute reduction in parental investments in girls. ${ }^{34}$

Moreover, the empirical relevance of concerns about wealth effects may be limited since the median Indian household is poor and is unlikely to hold significant stocks of gold in the absence of dowry. To investigate this directly, we assessed heterogeneity of the estimates with respect to household wealth. We expect wealthier households to be more likely to own gold, and as a result to be more responsive to wealth effects of gold price changes. Using quintiles of an index of household asset ownership, we find that the average results emerge from the poorer households in the bottom three quintiles, see Tables A.12 and A.13. The effect of gold price increases in increasing girl mortality is similar for wealthy and poorer households (the marginal effect for girls in the pre-85 period is 4 to 5 ppt for both), but for boys the effect is negative and significant among poorer households and insignificantly different from zero among the rich. This undermines the competing hypothesis that our

\footnotetext{
${ }^{33}$ Differences by whether or not average price growth was positive over the last 3 to 12 months are not statistically significant but the difference in the magnitudes is large.

${ }^{34}$ In fact though the coefficient is typically negative, we do not consistently see a significant tendency for gold price inflation to reduce boy mortality as would be predicted by wealth effects of gold price increases. In any case, as discussed earlier, if we did, this would be consistent with boys bringing in dowry.
} 
findings reflect wealth increases rather than dowry-increasing effects of gold price increases. Similarly, the result that the sex ratio becomes more girl-biased following gold price increases is driven by poorer households (the marginal effect in the post-85 period is 20ppt for the poor and insignificant for the rich) even though on average richer households commit more sex-selection (Bhalotra and Cochrane (2010)). ${ }^{35}$

Now suppose that gold, often held as jewelry, is the property of adult women. In this case, a wealth effect associated with an increase in gold prices could increase the bargaining power of women in the household. This is unlikely to be at play for two reasons. First, empowered women tend to favour daughters or else to treat daughters and sons equally, there is no clear evidence in the literature that empowered women favour sons (Thomas (1990), Baranov et al. (2017)). Moreover, Anderson and Bidner (2015) argue that dowry in India is typically appropriated by the husband and his parents, rather than remaining the property of the woman.

Setting aside the notion of gold as a store of wealth, might we be picking up income rather than relative price effects of gold price shocks? Gold price increases will create a negative income effect for net purchasers of gold that will tend to increase boy and girl mortality, but we see a tendency for boy mortality to decrease (or remain unchanged). It could be argued that this is consistent with son preference, with the income shock hurting girls alone. To investigate this further, we looked at the gender-differentiated impacts of income shocks in our sample. Recall that we controlled for income shocks using (monthly) oil price and rainfall shocks, each interacted with a girl dummy. These coefficients are displayed in Table A.7. We find that rainfall shortfalls (that reduce income) hurt girls more (like gold price shocks) but they also hurt boys (unlike gold price shocks). ${ }^{36}$ On the other hand, oil price increases do not seem to have a significant impact on boy or girl neonatal mortality (and the point estimates suggest they hurt boys more than they hurt girls).

\footnotetext{
${ }^{35}$ The wealth index is based on ownership of assets at the time of the survey, but ideally it would be based on assets at the birth date of children. Our estimates will thus be subject to noise and potentially to bias if households cross the 60-40 line in the wealth distribution. Notice that they allow for variation in wealth within these two crude groupings.

${ }^{36}$ Our estimates show that a one standard deviation decrease in rainfall (relative to its historical mean level in that month and state) is associated with a 0.5 percentage point increase in girl mortality pre-1985 (column 6 of Table A.7), and a very similar increase in excess girl mortality since rainshocks have a small and insignificant effect on boy mortality in this period, consistent with the evidence in Rose (1999). Using the same data source for India as used in this paper, for births that occur during 1970-1999, Bhalotra (2010) estimates that a 4.4 percent increase in state income (the median income shock in the sample period) led to a decrease in infant mortality of 0.25 percentage points for girls and, again, there was no change for boys, implying a 0.25 percentage point increase in excess girl infant mortality.
} 


\section{Conclusion}

Exploiting monthly time series variation in gold prices across 35 years, we provide what we believe is the first systematic evidence that the son-preferring behaviours of Indian parents respond to changes in the cost of dowry. We show, rather than assume, that dowry payments rise (almost) proportionally with gold prices. We conducted a number of checks that raise our confidence that we identify the impact of gold prices rather than of season, of omitted prices, or other omitted trends. We provide evidence to substantiate our claim that we are not capturing wealth or income effects of gold price shocks; the direction of responses of boy and girl mortality (and sex ratios) line up with the dowry hypothesis and not with the predicted impacts of wealth or income shocks.

Our findings implicate dowry as a substantial contributor to the phenomenon of missing girls. The mechanism prior to the mid-1980s appears to be post-birth neglect of girls. Consistent with this, we document significant impacts on survivors, showing that girls born during the gold price hike who survived to early adulthood were shorter, and we underline the importance of this by citing evidence that height is associated with a range of positive socioeconomic outcomes in the long run. After the mid-1980s, female foeticide becomes the predominant mechanism.

A vast literature has documented that Indian parents practice differential fertility stopping, commit female foeticide, and invest more in sons. These practices generate a malebiased population sex ratio, and numerous studies have documented what is possibly India's greatest embarrassment, the vast and growing number of missing women and girls. In this way, the outcomes of son preference are well-established. Yet there is surprisingly limited evidence on the causes of son preference, which often appears as a primitive. This is no doubt because it can be hard to find variation in institutional factors. We averted this problem by studying variation in the perceived cost of dowry.

Previous studies have attributed regional differences in son preference to time-invariant regional factors such as soil quality and crop choice that create variation in women's labour supply (Miller (1981), Carranza (2014)), and kinship systems that generate variation in how physically and economically distant daughters become from the natal home after marriage (Dyson and Moore (1983)). While these factors no doubt play a role, their impacts are hard to isolate from regional heterogeneity. By introducing gold prices into the analysis, we generate time variation that helps identification.

Although our primary contribution is to provide what we believe are the first estimates of the relevance of dowry costs to explaining the persistent problem of 'missing girls' in India, we also contribute to a literature on commodity price shocks and, more generally, the 
relationship between the macro-economy and intra-household resource allocation (Burgess and Zhuang (2000), Deaton and Tarozzi (2000), Qian (2008)).

\section{References}

Akresh, R., S. Bhalotra, M. Leone, and U. Osili (2012): "War and Stature: Growing up During the Nigerian Civil War," American Economic Review: Papers and Proceedings, 102, 273-77.

Almond, D. And L. Edlund (2008): "Son-Biased Sex Ratios in the 2000 United States Census," Proceedings of the National Academy of Sciences, 105, 5681-5682.

Almond, D., L. Edlund, And K. Milligan (2013): "Son Preference and the Persistence of Culture: Evidence from Asian Immigrants to Canada," The Population and Development Review.

Amrhein, V. And S. Greenland (2018): "Remove, Rather than Redefine, Statistical Significance," Nature Human Behaviour, 2, 4.

Anderson, S. (2003): "Why Dowry Payments Declined with Modernization in Europe but are Rising in India," Journal of Political Economy, 111, 269-310.

(2007): "The Economics of Dowry and Brideprice," Journal of Economic Perspectives, 21, 151-174.

Anderson, S. And C. Bidner (2015): "Property Rights over Marital Transfers," The Quarterly Journal of Economics, 130, 1421-1484.

Anderson, S. And D. Ray (2010): "Missing Women: Age and Disease." The Review of Economic Studies, 77, 1262-1300.

Anukriti, S., S. Bhalotra, And E. Tam (2015): "Missing Girls: Ultrasound Access, Fertility, and Gender Discrimination," Working Paper, Boston College.

Anukriti, S., S. Kwon, And N. Prakash (2017): "Dowry: Household Responses to Expected Marriage Payments," Working Paper, Boston College.

Arnold, F., M. K. Choe, And T. K. Roy (1998): "Son Preference, the Family-Building Process and Child Mortality in India," Population Studies, 52, 301-315.

Ashraf, N., N. Bau, N. Nunn, And A. Voena (2016): "Bride Price and Female Education," NBER Working Paper No. 22417.

Baranov, V., S. Bhalotra, And J. Maselko (2017): "The Ecology of Height: The Effect of Microbial Transmission on Human Height," IZA Working Paper.

Beard, A. S. And M. J. Blaser (2002): "The Ecology of Height: The Effect of Microbial Transmission on Human Height," Perspectives in Biology and Medicine, 45, 475-498. 
Becker, G. (1981): A Treatise on the Family, Harvard University Press. Cambridge, MA.

Bhalotra, S. (2010): "Fatal Fluctuations? Cyclicality in Infant Mortality in India," Journal of Development Economics, 93, 7-19.

Bhalotra, S. and T. Cochrane (2010): "Where Have All the Young Girls Gone? Identification of Sex Selection in India," IZA Discussion Papers 5381.

Bhalotra, S. And S. Rawlings (2011): "Intergenerational Persistence in Health in Developing Countries: The Penalty of Gender Inequality?" Journal of Public Economics, 95, 286-299.

Bhalotra, S., C. Valente, And A. van Soest (2010): "The Puzzle of Muslim Advantage in Child Survival in India," Journal of Health Economics, 29, 191-204.

Bhalotra, S. And A. van Soest (2008): "Birth-Spacing, Fertility and Neonatal Mortality in India: Dynamics, Frailty, and Fecundity," Journal of Econometrics, 143, 274-290.

Bharadwaj, P. and L. K. Lakdawala (2013): "Discrimination Begins in the Womb: Evidence of Sex-Selective Prenatal Investments," Journal of Human Resources, 48, 71-113.

Bhaskar, V. (2015): "The Demographic Transition and the Position of Women: A Marriage Market Perspective," CEPR Discussion Paper No. 10619.

BlOCh, F. AND V. RAO (2002): "Terror as a Bargaining Instrument: A Case Study of Dowry Violence in Rural India," American Economic Review, 1029-1043.

Bloch, F., V. RaO, and S. Desai (2004): "Wedding Celebrations as Conspicuous Consumption Signaling Social Status in Rural India," Journal of Human Resources, 39, 675695.

Borker, G., J. Eeckhour, N. Luke, S. Minz, K. Munshi, and S. Swaminathan (2017): "Wealth, Marriage, and Sex Selection," Working Paper, Cambridge University.

Borooah, V. And S. Iyer (2004): "Religion and Fertility in India: The Role of Son Preference and Daughter Aversion," Working Paper, University of Cambridge.

Boserup, E. (1970): Women in Economic Development, London: Earthscan.

Botticini, M. And A. Siow (2003): "Why Dowries?" American Economic Review, 93, 1385-98.

Bozzoli, C., A. Deaton, and C. Quintana-Domeque (2009): "Adult height and childhood disease," Demography, 46, 647-669.

Browning, M. and R. Subramaniam (1995): "Gender-Bias in India: Parental Preferences or Marriage Costs," Mimeograph, Yale University.

Burgess, R. And J. Zhuang (2000): "Modernisation and Son Preference," STICERD working paper. 
CarranzA, E. (2014): "Soil Endowments, Female Labor Force Participation, and the Demographic Deficit of Women in India," American Economic Journal: Applied Economics, $6,197-225$.

Case, A. And C. Paxson (2008): "Height, Health, and Cognitive Function at Older Ages," The American Economic Review, 98, 463-467.

Chakravarty, A. (2010): "Supply Shocks and Gender Bias in Child Health Investments: Evidence from the ICDS Programme in India," The B.E. Journal of Economic Analysis and Policy, 10, 1-26.

Chiplunkar, G. And J. Weaver (2017): "Marriage Markets and The Rise of Dowry in India," Working Paper, UCSD.

Corno, L., N. Hildebrandt, and A. Voena (2017): "Age of marriage, weather shocks and the direction of marriage payments," NBER Working Paper No. 23604.

Crimmins, E. M. And C. E. Finch (2006): "Infection, Inflammation, Height, and Longevity," Proceedings of the National Academy of Sciences of the United States of America, 103, 498-503.

Dai, A., K. Trenberth, And T. Qian (2004): "A Global Data Set of Palmer Drought Severity Index for 1870-2002: Relationship with Soil Moisture and Effects of Surface Warming," Journal of Hydrometeorology, 5, 1117-1130.

Deaton, A. And G. Laroque (1992): "On the Behaviour of Commodity Prices," The Review of Economic Studies, 40, 153-187.

Deaton, A. And A. Tarozzi (2000): "Prices and Poverty in India," Mimeo, Princeton University.

Deolalikar, A. (2007): "Human Development in India: Past Trends and Future Challenges," ASARC Working Papers 2007-17, The Australian National University, Australia South Asia Research Centre.

Deolalikar, A. And V. RaO (1998): Gender, Population and Development, Oxford: Oxford University Press, chap. The Demand for Dowries and Bride Characteristics in Marriage: Empirical Estimates for Rural South-Central India.

Desai, S. (1994): Gender Inequalities and Demographic Behavior, India, New York, 16.

Desai, S., A. Dubey, B. Joshi, M. Sen, A. Shariff, and R. Vanneman (2007): "India Human Development Survey (IHDS)," University of Maryland and National Council of Applied Economic Research, New Delhi. Ann Arbor, MI: Inter-university Consortium for Political and Social Research [distributor], 30 June 2009.

Doblhammer, G. And J. W. Vaupel (2001): "Lifespan Depends on Month of Birth," Proceedings of the National Academy of Sciences, 98, 2934-2939.

Dyson, T. And M. Moore (1983): "On Kinship Structure, Female Autonomy, and Demographic Behavior in India," Population and Development Review, 9, 35-60. 
Edlund, L. (2000): "The Marriage Squeeze Interpretation of Dowry Inflation: A Comment," Journal of Political Economy, 108, 1327-1333.

Elliott, G., T. Rothenberg, and J. Stock (1996): "Efficient Tests for an Autoregressive Unit Root," Econometrica, 64, 813-836.

Fogel, R. (2004): The Escape from Hunger and Premature Death, 1700-2100: Europe, America, and the Third World, vol. 38, Cambridge University Press.

Foster, A. And M. Rosenzweig (2006): "Does Economic Growth Reduce Fertility? Rural India: 1971-1999," Mimeograph.

Gadgil, S. And S. GadgIL (2006): "The Indian Monsoon, GDP and Agriculture," Economic and Political Weekly, 4887-4895.

George, S., R. Abel, And B. D. Miller (1992): "Female Infanticide in Rural South India," Economic and Political Weekly, 1153-1156.

Gupta, J. (2002): "Women Second in the Land Agenda," Economic and Political Weekly.

Harris, M. (1993): "The Evolution of Human Gender Hierarchies: A Trial Formulation," Sex and Gender Hierarchies, 57-79.

Hughes, D. (1978): "From Brideprice to Dowry in Mediterranean Europe," Journal of Family History.

Imbens, G. W. And M. Kolesár (2016): "Robust Standard Errors in Small Samples: Some Practical Advice," The Review of Economics and Statistics, 98, 701-712.

JADHAV, R. (2015): "Fall-off in Indian Weddings Bodes Ill for Jewellers, Gold," Reuters.

JaYAChandRan, S. (2014): "The Roots of Gender Inequality in Developing Countries," NBER Working Paper No. 20380.

Jayachandran, S. And I. Kuziemko (2011): "Why Do Mothers Breastfeed Girls Less than Boys? Evidence and Implications for Child Health in India," The Quarterly Journal of Economics, 126, 1485-1538.

Jejeebhoy, S. And Z. Sathar (2001): "Women's Autonomy in India and Pakistan: the Influence of Religion and Region," Population and Development Review, 27, 687-712.

Jha, P., R. Kumar, P. Vasa, N. Dhingra, D. Thiruchelvan, and R. Moineddin (2006): "Low Male-to-Female Sex Ratio of Children Born in India: National Survey of 1.1 Million Households," Lancet, 367, 211218.

Kannan, R. And D. Sarat (2008): "India's Demand for Gold: Some Issues for Economic Development and Macroeconomic Policy," Indian Journal of Economics and Business.

Kishor, S. And K. Gupta (2009): "Gender Equality and Womens Empowerment in India. National Family Health Survey (NFHS-3) India 2005-06." .

Kodoth, P. (2005): "Fostering Insecure Likelihoods: Dowry and Female Seclusion in Left Developmental Contexts in West Bengal and Kerala," Economics and Political Weekly. 
Kohli, A. (2006): "Politics of Economic Growth in India, 1980-2005," Economic and Political Weekly.

LeidL, P. (2005): "Silent Springs: The Tragedy of Indias Never-Born Girls," in The State of World Population, United Nations Population Fund.

Lowes, S. And N. Nunn (2017): "Bride Price and the Wellbeing of Women," WIDER Working Paper 2017/131.

M. Das Gupta, J. Zhenghuab, L. Bohuac, X. Zhenmingc, W. Chungd, and B. HwA-OKD (2003): "Why is Son preference so Persistent in East and South Asia? A Cross-Country Study of China, India and the Republic of Korea," The Journal of Development Studies, 40, 153-187.

Miller, B. (1981): The Endangered Sex: Neglect of Female Children in Rural North India, Ithaca, NY: Cornell University Press.

Moradi, A. (2010): "Nutritional Status and Economic Development in Sub-Saharan Africa, 1950-1980," Economics \& Human Biology, 8, 16-29.

Munshi, N. (2011): "Gold: Dulling India's Economy," The Financial Times.

Nomoto, T. (2016): "Rainfall Variability and Macroeconomic Performance: A Case Study of India, 1952-2013," Tech. rep., University Library of Munich, Germany.

Oster, E. (2009): "Does Increased Access Increase Equality? Health Investments and Gender Inequality in India," Journal of Development Economics, 89, 62-76.

QIAn, N. (2008): "Missing Women and the Price of Tea in China: The Effect of Sex-Specific Earnings on Sex Imbalance," The Quarterly Journal of Economics, 123, 1251-1285.

RAO, V. (1993): "The Rising Price of Husbands: A Hedonic Analysis of Dowry Increases in Rural India," Journal of Political Economy, 666-677.

REserve BANK of India (2013): "Report of the Working Group to Study the Issues Related to Gold Imports and Gold Loans NBFCs in India," .

Rocca, C., S. Rathod, T. Falle, R. Pande, and S. Krishnan (2009): "Challenging Assumptions About Women's Empowerment: Social and Economic Resources and Domestic Violence Among Young Married Women in Urban South India," International Journal of Epidemiology, 38, 577-585.

Rose, E. (1999): "Consumption Smoothing and Excess Female Mortality in Rural India," The Review of Economics and Statistics, 81, 41-49.

Rosenblum, D. (2013): "The Effect of Fertility Decisions on Excess Female Mortality in India," Journal of Population Economics, 26, 147-180.

Schwert, G. (1989): "Tests for Unit Roots: A Monte Carlo Investigation," Journal of Business and Economic Statistics. 
Sekhri, S. And A. Storeygard (2014): "Dowry Deaths: Response to Weather Variability in India," Journal of Development Economics.

SEn, A. (1992): "Missing Women." BMJ, 304, 587-588.

(2003): "Missing Women - Revisited." BMJ.

Smith, H., S. Ghuman, H. Lee, And K. Mason (2000): "Status of Women and Fertility," Machine-readable data file.

Srinivas, M. (1984): Some Reflections on Dowry., Delhi: Centre for Womens Development Studies.

SRInivasan, S. (2005): "Daughters or Dowries? The Changing Nature of Dowry Practices in South India," World Development, 33, 593-615.

Srivastava, I. (2012): "High Cost Takes Gold Down on Dowry List," The Times of India.

Strauss, J. And D. Thomas (2007): Handbook of Development Economics, vol. 4, chap. Health Over the Life Course, 3375-3474.

Tambiah, S. And J. Goody (1973): Bridewealth and Dowry, Cambridge UK: Cambridge University Press.

The World BAnk (2012): "World Development Report," Washington DC, USA.

Thomas, D. (1990): "Intra-Household Resource Allocation: An Inferential Approach," Journal of Human Resources, 635-664.

Thomas, D. And J. Strauss (1997): "Health and Wages: Evidence on Men and Women in Urban Brazil," Journal of Econometrics, 77, 159-185.

Vaidyanathan, A. (1999): "Consumption of Gold in India: Trends and Determinants," Economic and Political Weekly, 34, 471-476.

Virmani, A. (2006): "India's Economic Growth History: Fluctuations, Trends, Break Points and Phases," Indian Economic Review, 81-103.

WAAler, H. (1984): "Height. Weight and Mortality the Norwegian experience," Acta Medica Scandinavica, 215, 1-56.

WhHeed, A. (2009): "Dowry among Indian Muslims: Ideals and Practices," Indian Journal of Gender Studies, 16, 47-75.

Waldron, I. (1983): "Sex Differences in Human Mortality: The Role of Genetic Factors," Social Science \& Medicine, 17, 321-333.

World Gold Council (2002): "An Introduction to the Indian Gold Market," Fremantle, WA, Australia: Grendon International Research Pty Ltd. 
Figure 1: Gold Prices

(a) L(GOLD PRICE)

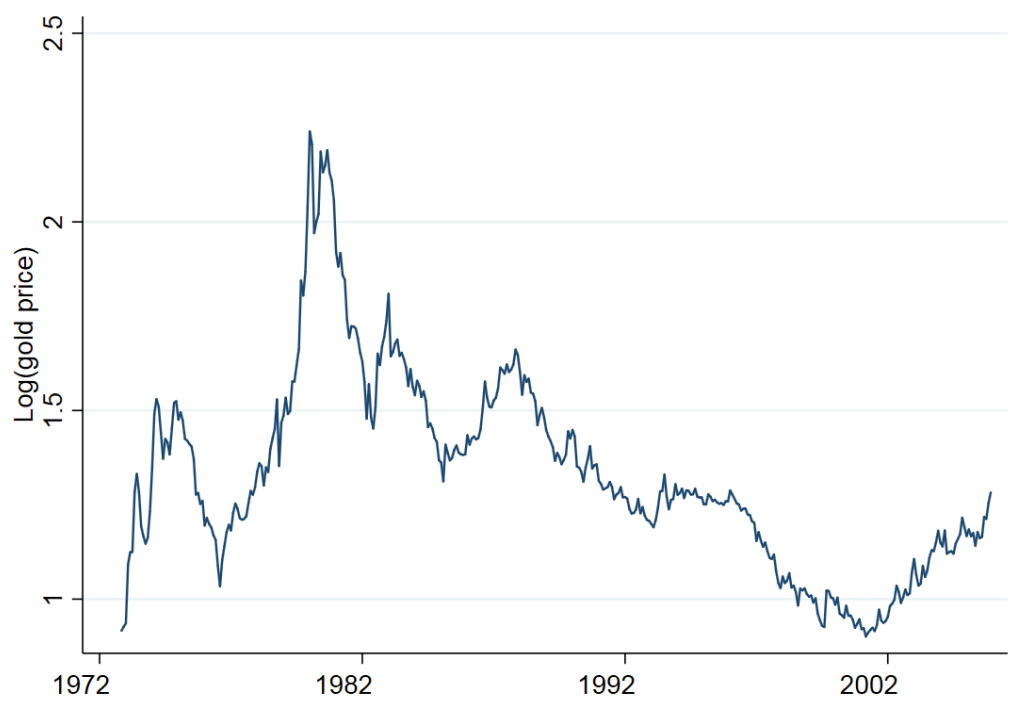

(b) $\Delta$ L (GOLD PRICE)

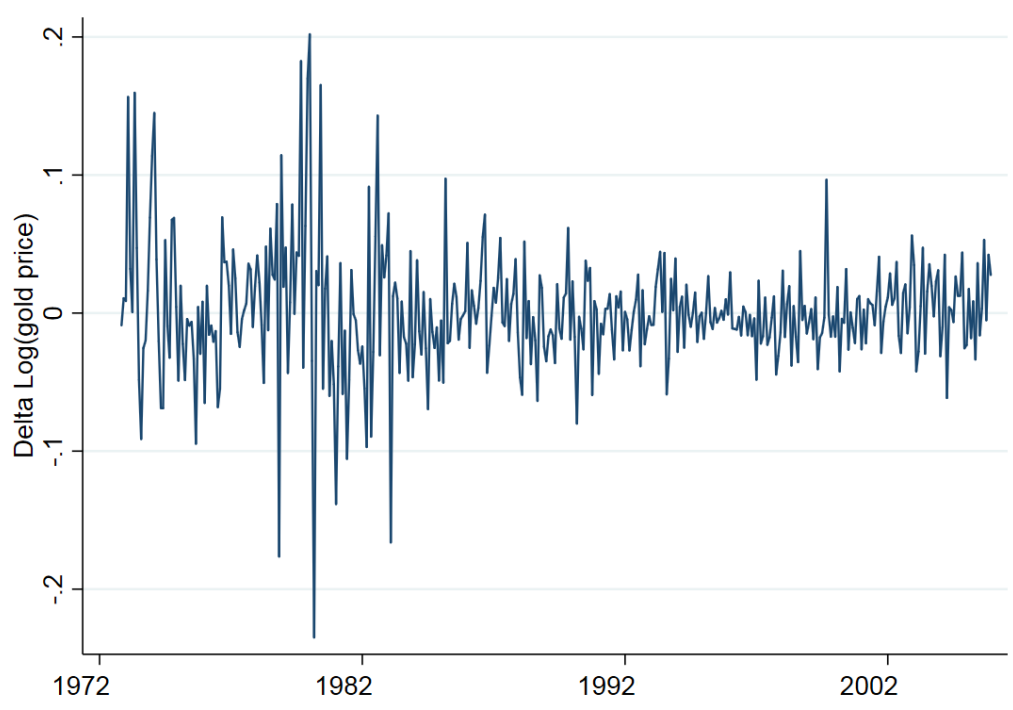

Notes: Figure A plots the log of monthly real gold price in the world market in USD between 1950-2005, deflated using the U.S.A. cpi values. Figure B shows the change in the log of monthly real gold price in the world market between 1950-2005. 


\section{Figure 2: NeOnatal mortality: Heterogeneity in the impaCt of POSITIVE GOLD PRICE SHOCKS BY WHETHER OR NOT GOLD PRICES HAVE SHOWN A SUSTAINED RISE IN THE N MONTHS PRECEDING BIRTH}

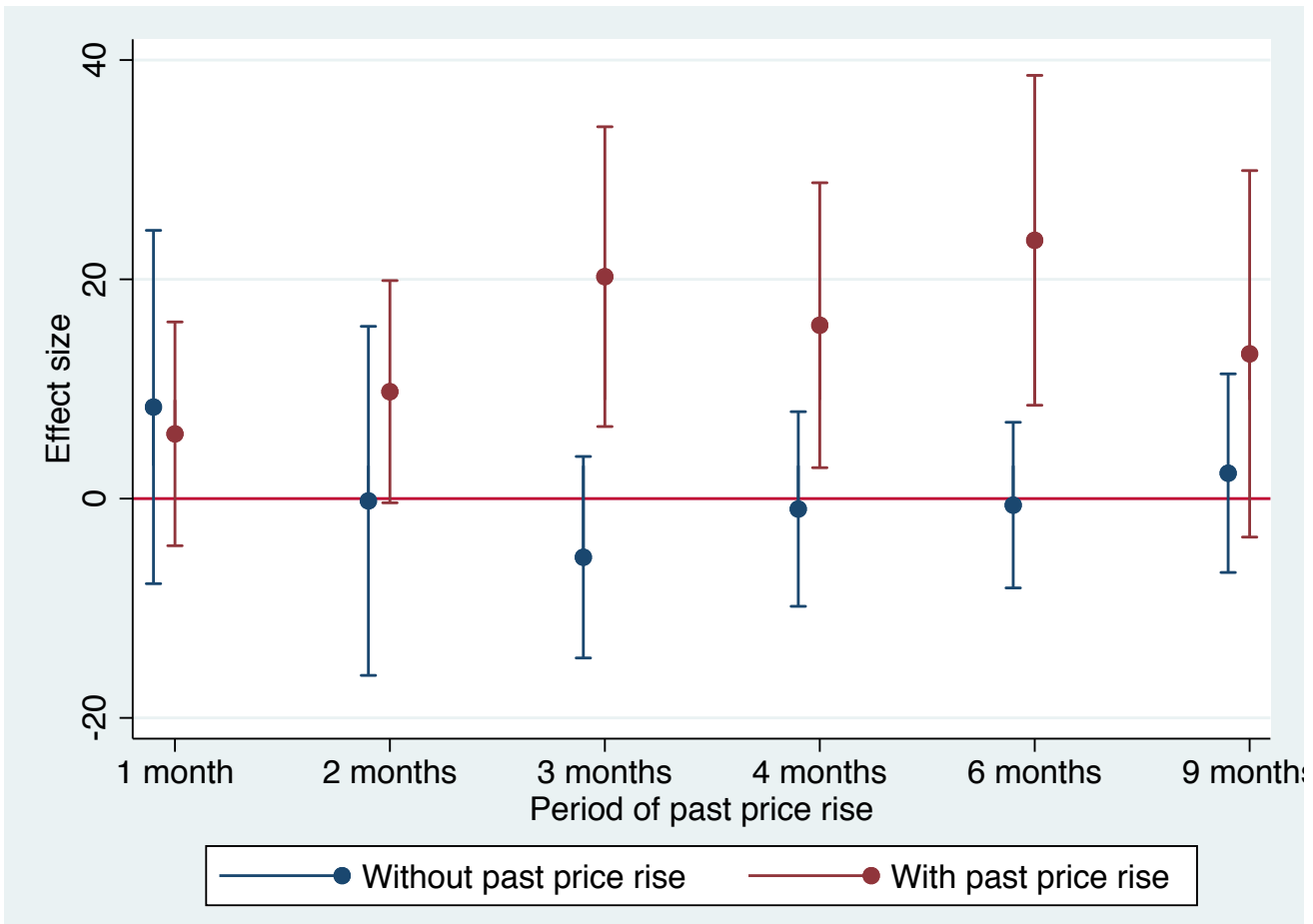

Notes: We estimate $y_{i t m s}=\alpha+\beta_{1} \cdot \operatorname{Pos}_{t m}+\lambda_{1} \cdot \operatorname{Pos}_{t m} \cdot f_{i}+\beta_{2} \cdot T_{t m-n}^{t m}+\lambda_{2} \cdot T_{t m-n}^{t m} \cdot f_{i}+\beta_{3} \cdot P_{o s} s_{t m} \cdot T_{t m-n}^{t m}+\lambda_{3}$. $\operatorname{Pos}_{t m} \cdot T_{t m-n}^{t m} \cdot f_{i}+\eta^{\prime}\left(Z_{t m} \cdot f_{i}\right)+\gamma^{\prime} X_{i t m s}+\theta_{t}+\kappa_{m}+\theta_{s}+\varepsilon_{i t}$ where $y_{i t m}$ is an indicator for neonatal mortality for individual $i$ born in month $m$ in year $t$ in state $s, \operatorname{Pos}_{t m}$ is an indicator for $\Delta l n P_{t m}>0, f$ indicates a female child, $T_{t m-n}^{t m}$ indicates whether the gold prices have been rising on average in the past $n$ months ending with tm. Sample is limited to second-born children born before 1985 (pre-ultrasound) in all the regressions. Gold prices are in USD, deflated using US CPI. All regressions control for state, year of birth and birth month fixed effects, a dummy variable $=1$ if the child's household was upper caste, a dummy variable for whether the child's eldest sibling was a boy, the linear and quadratic state-specific trends in month of birth; world oil price and oil price interacted with gender of the child; rainfall deviations from historical state-level mean in the month of birth, interacted with gender of the child. Standard errors are clustered by the month of birth $t$. The Figure plots the estimates and $90 \%$ confidence intervals for $\beta_{1}+\lambda_{1}+\beta_{3}+\lambda_{3}$, corresponding to the marginal effect of $\operatorname{Pos}_{t m}$ when $f=1$ (child is female) and $T_{t m-n}^{t m}=1$ (gold prices have been rising for the past $n$ months) for $n=1,2,3,4,6,9$. 


\section{Table 1: Summary Statistics}

\begin{tabular}{lccc}
\hline \hline & Mean & SD & Obs \\
\hline neonatal (0-1 month) mortality & 4.641 & & 103171 \\
girl neonatal mortality & 4.199 & 49412 \\
boy neonatal mortality & 5.047 & 53759 \\
probability girl child & 0.479 & & 103171 \\
share of families with first born sons & 0.511 & & 103171 \\
$\Delta$ L(gold price) & 0.001 & 0.045 & 398 \\
$\Delta$ L(gold price) before 1985 & 0.003 & 0.063 & 158 \\
$\Delta$ L(gold price) after 1985 & -0.000 & 0.026 & 240 \\
\hline \hline
\end{tabular}

Notes: The table shows the mean, standard deviation, and number of observations of key variables. Neonatal mortality is an indicator defined as 0 if the child survived the first month (year) of life and 100 if $\mathrm{s} /$ he died. The unit of observation is a child and the sample includes children of second birth order born in Hindu households between 1972 and 2005. In the last three rows, the unit of observation is a month.

\section{Table 2: Dowry Value And Gold Prices}

\begin{tabular}{lcccc}
\hline \hline & $(1)$ & $(2)$ & $(3)$ & $(4)$ \\
\hline L(gold price) & $0.854^{* * *}$ & $0.804^{* * *}$ & $0.796^{* * *}$ & $0.783^{* * *}$ \\
& $(0.221)$ & $(0.224)$ & $(0.228)$ & $(0.223)$ \\
Observations & 3847 & 3847 & 3755 & 3752 \\
& & & & \\
Additional macro controls & No & Yes & Yes & Yes \\
Age at marriage & No & No & Yes & Yes \\
Schooling & No & No & No & Yes \\
& & & & \\
Years in sample & $1970-99$ & $1970-99$ & $1970-99$ & $1970-99$ \\
\hline \hline
\end{tabular}

Notes: The table shows the results from estimating specification 1 where the dependent variable is the log real value of dowry payment made by the bride's side to the groom's side at the time of marriage. Data is from the 1999 wave of the Rural Economic and Demographic Survey, the sample is restricted to Hindu households. Log gold price is the log of the average monthly gold price in the year of marriage. Dowry is deflated using Indian CPI from World Bank Development Indicators, world commodity prices are deflated using US CPI. All regressions control for state fixed effects, caste of the bride's family and caste of the groom's family, number of brothers of the bride, number of sisters of the bride, world rice price and world oil price in the year of marriage, linear and quadratic trends in year of marriage. In addition, regression in column (2) controls for state GDP and state average rainfall; regression in column (3) controls for age of the bride at marriage and its square; regression in column (4) controls for the years of schooling of the bride and groom. Standard errors are clustered at the household level. 
Table 3: Neonatal Mortality

\begin{tabular}{|c|c|c|c|c|c|c|c|c|c|c|c|c|}
\hline \multirow[t]{2}{*}{ Time period: } & \multicolumn{3}{|c|}{$1972-2005$} & \multicolumn{3}{|c|}{ Pre-1985 } & \multicolumn{3}{|c|}{ Post-1985 } & \multicolumn{3}{|c|}{ 1972-2005: Interactions } \\
\hline & (1) & $(2)$ & $(3)$ & $(4)$ & $(5)$ & (6) & (7) & $(8)$ & (9) & $(10)$ & $(11)$ & $(12)$ \\
\hline$\Delta \mathrm{L}($ gold price $)$ & $\begin{array}{l}-3.446 \\
(2.344)\end{array}$ & $\begin{array}{c}-3.911^{*} \\
(2.350)\end{array}$ & & $\begin{array}{c}-4.353^{*} \\
(2.602)\end{array}$ & $\begin{array}{l}-4.403 \\
(2.704)\end{array}$ & & $\begin{array}{l}-3.856 \\
(4.136)\end{array}$ & $\begin{array}{l}-5.020 \\
(4.139)\end{array}$ & & $\begin{array}{l}-3.581 \\
(2.732)\end{array}$ & $\begin{array}{l}-3.630 \\
(2.706)\end{array}$ & \\
\hline$\Delta \mathrm{L}($ gold price $) \times \operatorname{girl}$ & $\begin{array}{l}5.410^{*} \\
(3.108)\end{array}$ & $\begin{array}{l}5.812^{*} \\
(3.056)\end{array}$ & $\begin{array}{c}6.081^{* *} \\
(3.060)\end{array}$ & $\begin{array}{l}7.722^{* *} \\
(3.536)\end{array}$ & $\begin{array}{c}7.536^{* *} \\
(3.638)\end{array}$ & $\begin{array}{l}7.924^{* *} \\
(3.645)\end{array}$ & $\begin{array}{c}0.370 \\
(5.949)\end{array}$ & $\begin{array}{c}1.496 \\
(5.643)\end{array}$ & $\begin{array}{c}1.469 \\
(5.642)\end{array}$ & $\begin{array}{l}7.816^{* *} \\
(3.551)\end{array}$ & $\begin{array}{l}7.905^{* *} \\
(3.535)\end{array}$ & $\begin{array}{l}8.326^{* *} \\
(3.553)\end{array}$ \\
\hline$\Delta \mathrm{L}($ gold price $) \times$ post -1985 & & & & & & & & & & $\begin{array}{c}0.316 \\
(4.982)\end{array}$ & $\begin{array}{l}-1.042 \\
(4.955)\end{array}$ & \\
\hline$\Delta \mathrm{L}($ gold price $) \times$ post $-1985 \times$ girl & & & & & & & & & & $\begin{array}{l}-7.387 \\
(6.884)\end{array}$ & $\begin{array}{l}-6.529 \\
(6.625)\end{array}$ & $\begin{array}{l}-7.070 \\
(6.640)\end{array}$ \\
\hline Mean for girls & 4.199 & 4.199 & 4.199 & 5.096 & 5.096 & 5.096 & 3.834 & 3.834 & 3.834 & 4.199 & 4.199 & 4.199 \\
\hline Mean for boys & 5.047 & 5.047 & 5.047 & 6.458 & 6.458 & 6.458 & 4.483 & 4.483 & 4.483 & 5.047 & 5.047 & 5.047 \\
\hline Marginal effect for girls & $\begin{array}{c}1.964 \\
(2.057)\end{array}$ & $\begin{array}{c}1.901 \\
(2.034)\end{array}$ & & $\begin{array}{c}3.369 \\
(2.571)\end{array}$ & $\begin{array}{c}3.133 \\
(2.621)\end{array}$ & & $\begin{array}{l}-3.485 \\
(3.463)\end{array}$ & $\begin{array}{l}-3.524 \\
(3.242)\end{array}$ & & $\begin{array}{l}4.235^{*} \\
(2.461)\end{array}$ & $\begin{array}{l}4.276^{*} \\
(2.461)\end{array}$ & \\
\hline Marginal effect for boys post- 1985 & & & & & & & & & & $\begin{array}{l}-3.265 \\
(4.191)\end{array}$ & $\begin{array}{l}-4.672 \\
(4.210)\end{array}$ & \\
\hline Marginal effect for girls post- 1985 & & & & & & & & & & $\begin{array}{l}-2.836 \\
(3.550)\end{array}$ & $\begin{array}{l}-3.296 \\
(3.396)\end{array}$ & $\begin{array}{c}1.256 \\
(5.635)\end{array}$ \\
\hline Observations & 103171 & 103171 & 103171 & 29651 & 29651 & 29651 & 73520 & 73520 & 73520 & 103171 & 103171 & 103171 \\
\hline Time-series controls & No & Yes & Yes & No & Yes & Yes & No & Yes & Yes & No & Yes & Yes \\
\hline Month $\times$ year of birth fixed effects & No & No & Yes & No & No & Yes & No & No & Yes & No & No & Yes \\
\hline
\end{tabular}

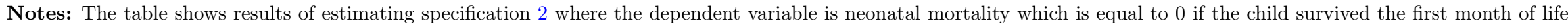

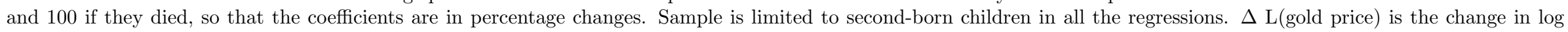

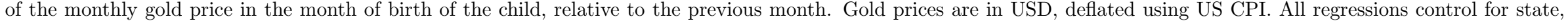

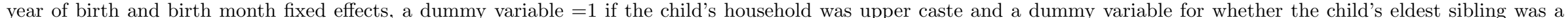

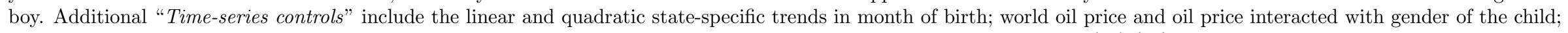

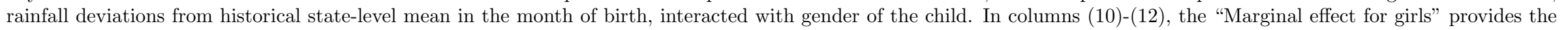
marginal effect pre-1985. Standard errors are clustered by month $\times$ year of birth. 
Table 4: Neonatal Mortality: Robustness Check

\begin{tabular}{lcccccc}
\hline \hline & \multicolumn{3}{c}{ Pooled OLS } & \multicolumn{3}{c}{ With Mother Fixed Effects } \\
\hline$\Delta$ L(gold price) & $(1)$ & $(2)$ & $(3)$ & $(4)$ & $(5)$ & $(6)$ \\
& -0.523 & -0.910 & & 0.519 & 0.152 & \\
$\Delta$ L (gold price) $\times$ girl & $(1.745)$ & $(1.757)$ & & $(2.238)$ & $(2.505)$ & \\
& 2.719 & 2.943 & 3.040 & 4.051 & 4.334 & 4.546 \\
& $(2.469)$ & $(2.509)$ & $(2.524)$ & $(3.224)$ & $(3.330)$ & $(3.314)$ \\
\hline Mean for girls & 5.023 & 5.023 & 5.023 & 5.023 & 5.023 & 5.023 \\
Mean for boys & 5.607 & 5.607 & 5.607 & 5.607 & 5.607 & 5.607 \\
Marginal effect for girls & 2.196 & 2.033 & & $4.570^{* * *}$ & $4.487^{* * *}$ & \\
& $(1.475)$ & $(1.496)$ & & $(2.091)$ & $(2.371)$ & \\
Observations & 201321 & 201321 & 201321 & 201321 & 201321 & 201321 \\
Time-series controls & No & Yes & Yes & No & Yes & Yes \\
Month $\times$ year of birth fixed effects & No & No & Yes & No & No & Yes \\
Mother fixed effects & No & No & No & Yes & Yes & Yes \\
\hline \hline
\end{tabular}

Notes: The table shows results of estimating specification 2 where the dependent variable is an indicator for neonatal mortality, defined as 0 if the child survived the first month of life and 100 if they died, so that the coefficients are in percentage changes. Sample includes mothers who have at least 3 children; and all children of second or higher birth order. $\Delta$ L(gold price) is the change in $\log$ of the monthly gold price in the month of birth of the child, relative to the previous month. Gold prices are in USD, deflated using US CPI. All regressions control for state, year of birth and birth month fixed effects, a dummy variable $=1$ if the child's household was upper caste and a dummy variable for whether the child's eldest sibling was a boy. Additional Time-series controls include the linear and quadratic state-specific trends in month of birth; world oil price and oil price interacted with gender of the child; rainfall deviations from historical state-level mean in the month of birth, interacted with gender of the child. Standard errors are clustered by month $\times$ year of birth. 


\section{Table 5: Sex Ratio AT BiRTh}

\begin{tabular}{|c|c|c|c|c|c|c|c|c|}
\hline \multirow[t]{2}{*}{ Time period: } & \multicolumn{2}{|c|}{$1972-2005$} & \multicolumn{2}{|c|}{ Pre-1985 } & \multicolumn{2}{|c|}{ Post-1985 } & \multicolumn{2}{|c|}{ 1972-2005 } \\
\hline & (1) & $(2)$ & $(3)$ & (4) & (5) & (6) & (7) & (8) \\
\hline$\Delta \mathrm{L}$ (gold price) & -3.520 & -4.089 & -0.300 & 1.132 & -8.739 & $-12.147^{* *}$ & -1.696 & -1.841 \\
\hline & $(3.245)$ & $(3.331)$ & $(3.714)$ & $(3.819)$ & $(6.079)$ & $(6.056)$ & $(3.776)$ & $(3.747)$ \\
\hline$\Delta \mathrm{L}($ gold price $) \times$ post -1985 & & & & & & & $\begin{array}{l}-6.990 \\
(7.116)\end{array}$ & $\begin{array}{l}-9.311 \\
(6.942)\end{array}$ \\
\hline Sample mean & 47.893 & 47.893 & 48.248 & 48.248 & 47.750 & 47.750 & 47.893 & 47.893 \\
\hline Marginal effect post-1985 & & & & & & & $\begin{array}{l}-8.686 \\
(6.049)\end{array}$ & $\begin{array}{c}-11.152^{*} \\
(6.046)\end{array}$ \\
\hline Observations & 103171 & 103171 & 29651 & 29651 & 73520 & 73520 & 103171 & 103171 \\
\hline \multicolumn{9}{|c|}{ Panel B: Heterogeneity by Gender of First Child } \\
\hline$\Delta \mathrm{L}($ gold price $)$ & $\begin{array}{c}-10.081^{* *} \\
(4.690)\end{array}$ & $\begin{array}{c}-10.629^{* *} \\
(4.759)\end{array}$ & $\begin{array}{l}-4.544 \\
(5.089)\end{array}$ & $\begin{array}{l}-2.912 \\
(5.225)\end{array}$ & $\begin{array}{c}-21.543^{* * *} \\
(7.568)\end{array}$ & $\begin{array}{c}-24.903^{* * *} \\
(7.554)\end{array}$ & $\begin{array}{l}-6.004 \\
(5.237)\end{array}$ & $\begin{array}{l}-6.125 \\
(5.194)\end{array}$ \\
\hline$\Delta \mathrm{L}($ gold price $) \times$ first son & $\begin{array}{c}12.965^{* *} \\
(6.181)\end{array}$ & $\begin{array}{c}12.908^{* *} \\
(6.217)\end{array}$ & $\begin{array}{c}8.418 \\
(6.272)\end{array}$ & $\begin{array}{c}7.976 \\
(6.335)\end{array}$ & $\begin{array}{c}25.068^{* *} \\
(12.127)\end{array}$ & $\begin{array}{c}25.046^{* *} \\
(12.124)\end{array}$ & $\begin{array}{c}8.436 \\
(6.245)\end{array}$ & $\begin{array}{c}8.413 \\
(6.264)\end{array}$ \\
\hline$\Delta \mathrm{L}($ gold price $) \times$ post -1985 & & & & & & & $\begin{array}{c}-15.479^{*} \\
(9.146)\end{array}$ & $\begin{array}{c}-17.781^{* *} \\
(9.026)\end{array}$ \\
\hline$\Delta \mathrm{L}($ gold price $) \times$ post $-1985 \times$ first son & & & & & & & $\begin{array}{c}16.557 \\
(13.589)\end{array}$ & $\begin{array}{c}16.496 \\
(13.636)\end{array}$ \\
\hline Sample mean & 47.893 & 47.893 & 48.248 & 48.248 & 47.750 & 47.750 & 47.893 & 47.893 \\
\hline Marginal effect if eldest sibling male & $\begin{array}{c}2.884 \\
(4.246)\end{array}$ & $\begin{array}{c}2.279 \\
(4.333)\end{array}$ & $\begin{array}{c}3.874 \\
(4.603)\end{array}$ & $\begin{array}{c}5.064 \\
(4.678)\end{array}$ & $\begin{array}{c}3.525 \\
(9.469)\end{array}$ & $\begin{array}{c}0.144 \\
(9.445)\end{array}$ & $\begin{array}{c}2.432 \\
(4.502)\end{array}$ & $\begin{array}{c}2.288 \\
(4.520)\end{array}$ \\
\hline Marginal effect post-1985 & & & & & & & $\begin{array}{c}-21.483^{* * *} \\
(7.510)\end{array}$ & $\begin{array}{c}-23.906^{* * *} \\
(7.489)\end{array}$ \\
\hline Marginal effect post-1985 if eldest sibling male & & & & & & & $\begin{array}{c}3.510 \\
(9.456)\end{array}$ & $\begin{array}{c}1.003 \\
(9.498)\end{array}$ \\
\hline Observations & 103171 & 103171 & 29651 & 29651 & 73520 & 73520 & 103171 & 103171 \\
\hline Time-series controls & No & Yes & No & Yes & No & Yes & No & Yes \\
\hline
\end{tabular}

Notes: The table shows results of estimating specification 2 where the dependent variable is an indicator for the gender of the child being a girl, multiplied by 100. Sample is limited to second-born children in all the regressions. $\Delta \mathrm{L}$ (gold price) is the change in log of the quarterly gold price in the three months leading up to the birth of the child (i.e. the final trimester), relative to the previous three months. Gold prices are in USD, deflated using US CPI. All regressions control for state, year of birth and birth month fixed effects, a dummy variable $=1$ if the child's household was upper caste and a dummy variable for whether the child's eldest sibling was a boy. Additional "Time-series controls" include the linear and quadratic state-specific trends in month of birth; world oil price; rainfall deviations from historical state-level mean in the month of birth and their lags up to 12 months preceding the birth. In Panel B, "first son" is a dummy variable =1 if the eldest sibling of the child (i.e. the first-born child of the parents of the child) is a boy, and 0 otherwise. Standard errors are clustered by month $\times$ year of birth. 
Table 6: Height

\begin{tabular}{lccccc}
\hline \hline & \multicolumn{3}{c}{ Full Sample } & \multicolumn{2}{c}{ Girls } \\
\hline & Panel A: Prices during & Month of Birth & & $(4)$ \\
\hline & $1.880^{* *}$ & $1.721^{*}$ & & 0.215 & 0.178 \\
\hline$\Delta$ L(gold price) & $(0.952)$ & $(1.004)$ & & $(0.386)$ & $(0.397)$ \\
$\Delta$ L(gold price) $\times$ girl & $-1.746^{*}$ & -1.585 & -1.590 & & \\
& $(0.961)$ & $(0.992)$ & $(0.990)$ & & \\
\hline Mean for girls & 151.707 & 151.707 & 151.707 & 151.707 & 151.707 \\
Mean for boys & 164.716 & 164.716 & 164.716 & & \\
Marginal effect for girls & 0.134 & 0.136 & & & \\
& $(0.386)$ & $(0.399)$ & & & \\
Observations & 56535 & 56535 & 56535 & 44296 & 44296 \\
\hline & Panel B: Prices during & Year of & Birth & & \\
\hline$\Delta$ L(gold price) & -0.100 & -0.274 & & $-0.435^{*}$ & $-0.492^{*}$ \\
& $(0.346)$ & $(0.411)$ & & $(0.261)$ & $(0.279)$ \\
$\Delta$ L(gold price) $\times$ girl & -0.248 & -0.062 & -0.071 & & \\
& $(0.276)$ & $(0.349)$ & $(0.350)$ & & \\
\hline Mean for girls & 151.707 & 151.707 & 151.707 & 151.707 & 151.707 \\
Mean for boys & 164.716 & 164.716 & 164.716 & & \\
Marginal effect for girls & -0.347 & -0.337 & & & \\
& $(0.272)$ & $(0.285)$ & & & \\
Observations & 56535 & 56535 & 56535 & 44296 & 44296 \\
Time-series controls & No & Yes & Yes & No & Yes \\
Month $\times$ year of birth fixed effects & No & No & Yes & No & No \\
\hline \hline
\end{tabular}

Notes: The table shows results of estimating specification 2 where the dependent variable is height of the adult female respondent in NFHS rounds 2 , or adult male or female respondents in NFHS round 3 (men's height was not measured in other NFHS rounds). The birth years of respondents range from 1972 to 1991 . The sample is restricted to Hindu respondents. In Panel $\mathrm{A}, \Delta \mathrm{L}$ (gold price) is the change in log of the monthly gold price in the month of birth of the child, relative to the previous month. In Panel $\mathrm{B}, \Delta \mathrm{L}$ (gold price) is the change in log of the average monthly gold price during the first 12 months of the child's life, relative to the previous 12 months. Gold prices are in USD, deflated using US CPI. All regressions control for state, year of birth and birth month fixed effects and a dummy variable $=1$ if the respondent's household was upper caste. Additional Time-series controls include the linear and quadratic state-specific trends in month of birth; world oil price and oil price interacted with gender of the child; rainfall deviations from historical state-level mean in the month of birth, interacted with gender of the child. Standard errors are clustered by month $\times$ year of birth. 


\section{A Appendix: Additional Tables and Figures}

Figure A.1: Silver AND Gold PRICES

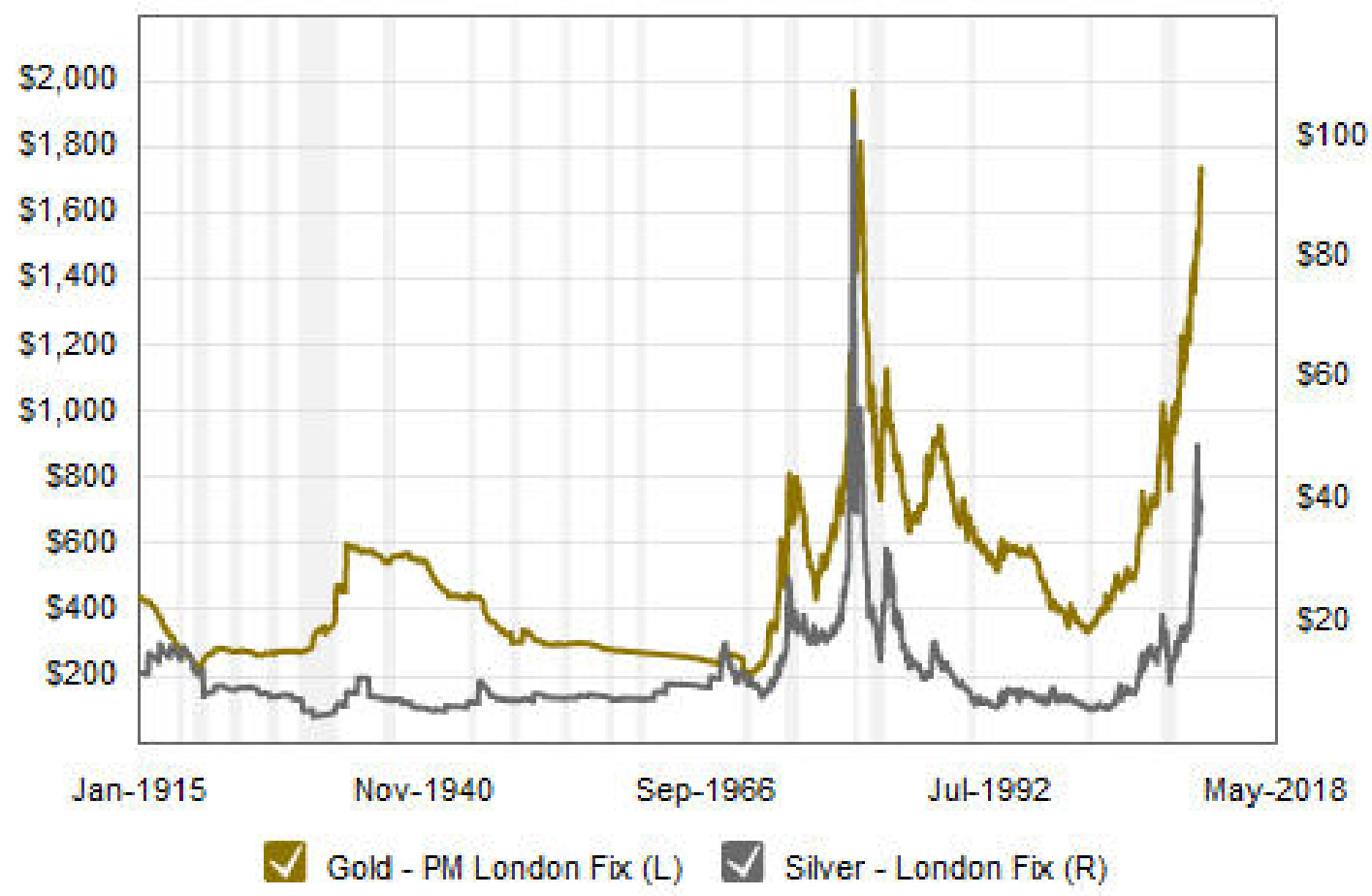

Notes: Figure shows gold and silver prices in USD per troy ounce from the London Stock Exchange, taken from seekingalpha.com. 


\section{Figure A.2: Event Study - Neonatal Mortality around Dec'79}

(a) Females

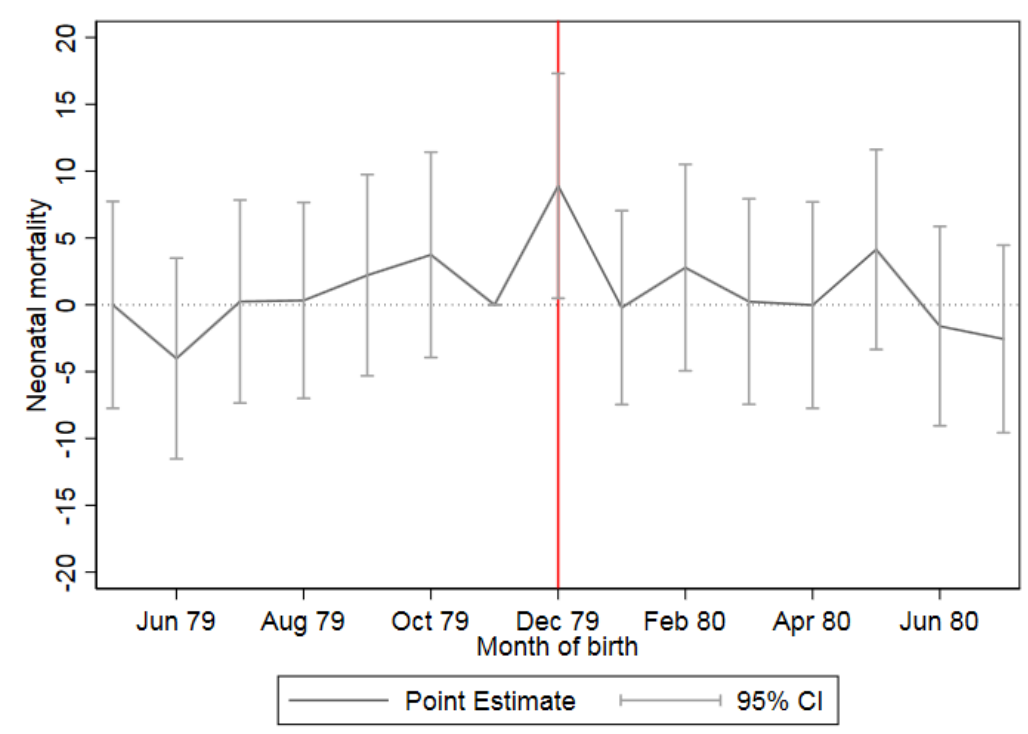

(b) Males

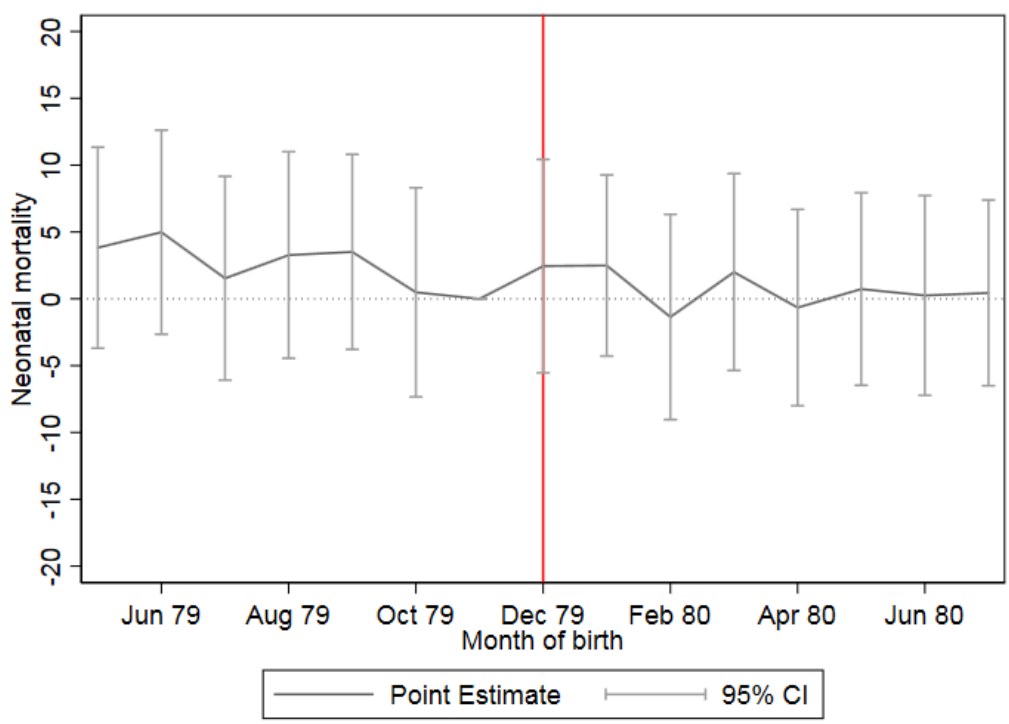

Notes: The estimated equation is $y_{i t s}=\sum_{t=-7}^{7} \beta_{t}+\sum_{t=-7}^{7} \sum_{k=-14}^{0} \alpha_{t+k} \cdot$ rainfall $_{t+k, s}+\gamma^{\prime} X_{i}+\theta_{s}+\varepsilon_{i t m}$ where $y_{i t s}$ is an indicator for neonatal mortality for individual $i$ born in month $t$ in state $s$. Figure plots the coefficient estimates and 90\% confidence intervals for $\beta_{t}$. Month -1 is set to zero as the base case. Sample includes female (in Panel A) and male (in Panel B) children of second birth orders born to Hindu families between \pm 7 months around December 1979. Control variables are a dummy variable $=1$ if the child's household was upper caste, birth order of the child and a dummy variable for whether the child's eldest sibling was a boy, state-level rainfall shocks defined as deviations from historical state-level mean in the month of birth and its lags. Standard errors are clustered at month $\times$ year of birth level, following Imbens and Kolesár (2016) to adjust for small number of clusters. Using deseasonalized mortality risk makes no difference to the estimates. 
Figure A.3: Neonatal mortality rates for GiRls and boys: monthly time Series DATA

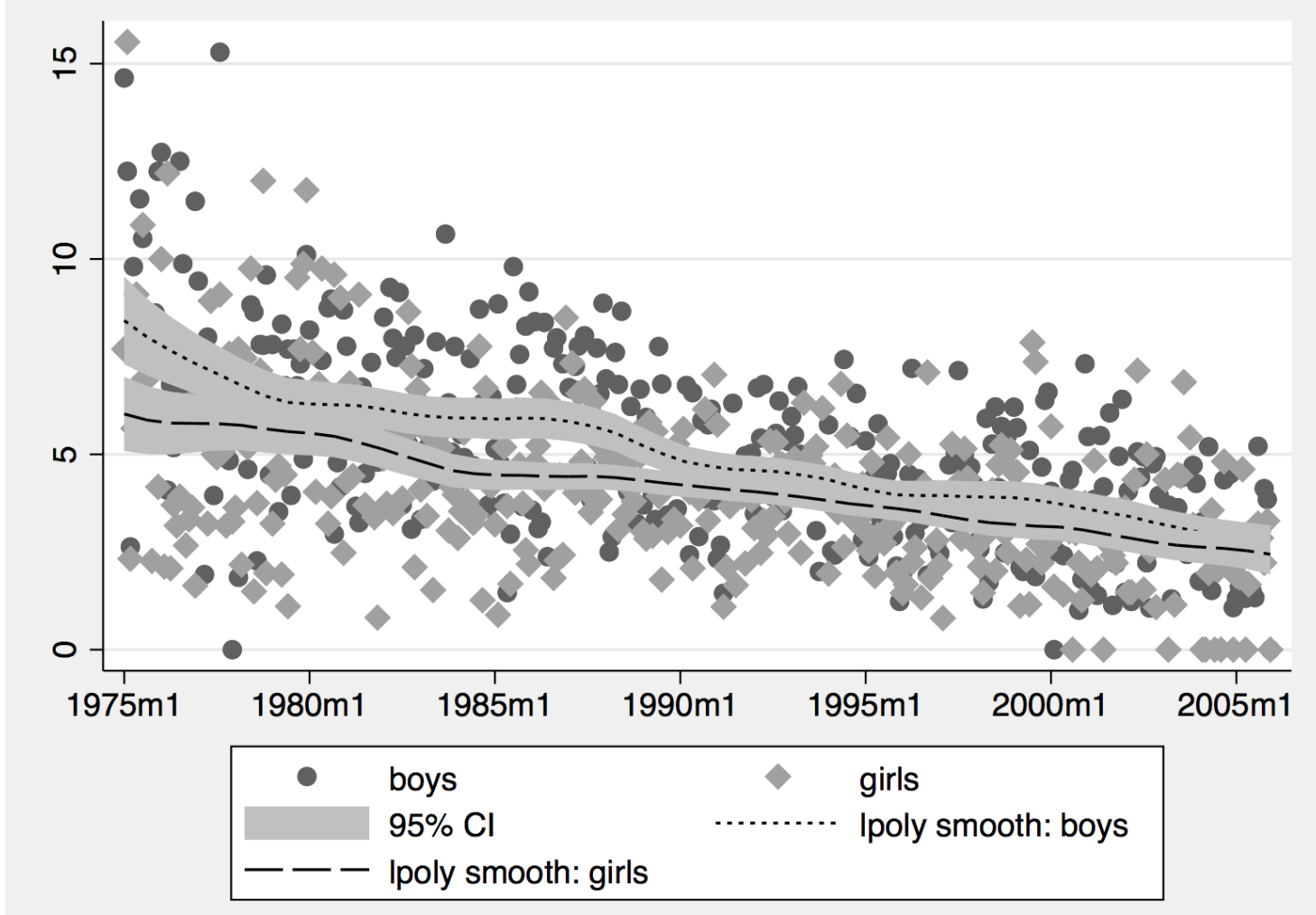

Notes: Figure plots the average monthly neonatal mortality rate for boys and girls in the NFHS dataset. 


\section{A.1 Gold Prices Follow A Random Walk}

In order to test whether gold prices follow a random walk, we conduct two tests, varying the null. We first run the Augmented Dickey-Fuller test (ADF) for gold prices $p_{t}$ using the model

$$
p_{t}=\alpha+\delta t+\phi p_{t-1}+\epsilon_{t}
$$

where $\alpha=\sum_{k=1}^{t-1} \epsilon_{k}$ is a drift constant term, and $t$ is a linear trend. If $p_{t}$ follows a random walk, we should fail to reject the null hypothesis of a unit root, $H_{0}: \phi=1$. We perform the DF-GLS version of the test proposed in Elliott et al. (1996), which is a modified version of the ADF performed on a GLS detrended series of $p_{t}$ that has greater power with a finite sample size. We additionally perform a KPSS test for gold price stationarity (which reverses the null relative to the previous test) using the model:

$$
\begin{aligned}
& p_{t}=\boldsymbol{\beta}^{\prime} \boldsymbol{D}_{t}+\mu_{t}+u_{t} \\
& \mu_{t}=\mu_{t-1}+\epsilon_{t}, \quad \epsilon_{t} \backsim W N\left(0, \sigma_{\epsilon}^{2}\right)
\end{aligned}
$$

where $\boldsymbol{D}_{t}$ contains a constant and a linear time trend in $t$, and $u_{t}$ is trend stationary, or $I(0)$, and allowed to be heteroskedastic. $\mu_{t}$ is a random walk with innovation variance $\sigma_{\epsilon}^{2}$. The null hypothesis in this test is that gold prices are trend stationary, or $H_{0}: \sigma_{\epsilon}^{2}=0$ which implies that $\mu_{t}$ is a constant. Failure to reject $H_{0}$ would indicate that gold price evolution over time is a mean-reverting process, rather than a random walk. In both the DF-GLS and KPSS tests, we allow for the optimal number of lags in $p_{t}$ as determined by the criterion proposed in Schwert (1989) to be included in the specifications.

The estimates in Table A.1 indicate that gold prices follow a random walk in our time series sample. The estimates from the DF-GLS test in column (1) show that the null hypothesis $H_{0}: \phi=1$ is never rejected at the $5 \%$ level, with up to 17 lag terms included in the covariates when estimating equation (3). Conversely, the estimates from the KPSS test in column (3) show that the null hypothesis $H_{0}: \sigma_{\epsilon}^{2}=0$ is always rejected at the $5 \%$ level with up to 17 lags included when estimating (4). In view of this evidence, we take the first difference of the logarithm of gold prices in the analysis and, as is clear from Figure 1b, this looks like white noise. 
Table A.1: Gold Prices - Random Walk Test

\begin{tabular}{lcccc}
\hline \hline & $(1)$ & $(2)$ & $(3)$ & $(4)$ \\
\hline \multicolumn{3}{c}{ DLF-GLS } & \multicolumn{3}{c}{ KPSS } \\
\hline Lags & Test Statistic & $5 \%$ Critical Value & Test Statistic & $5 \%$ Critical Value \\
\hline 17 & -1.679 & -2.816 & 0.236 & 0.146 \\
16 & -1.825 & -2.821 & 0.246 & 0.146 \\
15 & -1.862 & -2.826 & 0.258 & 0.146 \\
14 & -1.877 & -2.831 & 0.271 & 0.146 \\
13 & -2.023 & -2.836 & 0.286 & 0.146 \\
12 & -2.112 & -2.841 & 0.304 & 0.146 \\
11 & -2.443 & -2.846 & 0.325 & 0.146 \\
10 & -2.014 & -2.850 & 0.350 & 0.146 \\
9 & -2.059 & -2.855 & 0.380 & 0.146 \\
8 & -1.854 & -2.859 & 0.417 & 0.146 \\
7 & -1.746 & -2.863 & 0.464 & 0.146 \\
6 & -1.533 & -2.867 & 0.524 & 0.146 \\
5 & -1.739 & -2.871 & 0.605 & 0.146 \\
4 & -1.553 & -2.875 & 0.718 & 0.146 \\
3 & -1.381 & -2.879 & 0.887 & 0.146 \\
2 & -1.504 & -2.883 & 1.17 & 0.146 \\
1 & -1.687 & -2.886 & 1.73 & 0.146 \\
\hline \hline
\end{tabular}

Notes: The monthly gold price data on which the tests are conducted spans the period 1973-2005, and contains 390 observations. 
Table A.2: Neonatal mortality: Heterogeneity By Shock size AND ASYMMETRY IN RESPONSES TO GOLD PRICE RISES VS PRICE FALLS

\begin{tabular}{|c|c|c|c|c|c|c|c|c|c|}
\hline \multirow[t]{2}{*}{ Time period: } & \multicolumn{3}{|c|}{$1972-2005$} & \multicolumn{3}{|c|}{ Pre-1985 } & \multicolumn{3}{|c|}{ Post-1985 } \\
\hline & $(1)$ & $(2)$ & $(3)$ & $(4)$ & $(5)$ & $(6)$ & $(7)$ & $(8)$ & $(9)$ \\
\hline \multirow[t]{2}{*}{ Gold price fall } & 0.104 & 0.026 & & -1.416 & -1.517 & & 0.249 & 0.204 & \\
\hline & $(0.374)$ & $(0.373)$ & & $(1.754)$ & $(1.665)$ & & $(0.364)$ & $(0.355)$ & \\
\hline \multirow[t]{2}{*}{ Price fall $\times$ girl } & -0.027 & 0.063 & 0.120 & 2.326 & $2.280^{*}$ & $2.428^{*}$ & -0.109 & -0.046 & 0.004 \\
\hline & $(0.520)$ & $(0.509)$ & $(0.516)$ & $(1.435)$ & $(1.337)$ & $(1.369)$ & $(0.525)$ & $(0.510)$ & $(0.518)$ \\
\hline \multirow[t]{2}{*}{ Large price shock } & 0.359 & 0.211 & & -1.871 & -1.973 & & $0.931^{*}$ & 0.757 & \\
\hline & $(0.429)$ & $(0.422)$ & & $(1.683)$ & $(1.645)$ & & $(0.528)$ & $(0.511)$ & \\
\hline \multirow[t]{2}{*}{ Large price shock $\times$ girl } & -0.111 & 0.009 & 0.078 & $3.789^{* * *}$ & $3.820^{* * *}$ & $3.996^{* * *}$ & -1.080 & -0.898 & -0.904 \\
\hline & $(0.647)$ & $(0.606)$ & $(0.609)$ & $(1.338)$ & $(1.247)$ & $(1.285)$ & $(0.918)$ & $(0.832)$ & $(0.833)$ \\
\hline \multirow[t]{2}{*}{ Large price shock $\times$ price fall } & 0.489 & 0.667 & & 2.778 & 2.892 & & -0.648 & -0.461 & \\
\hline & $(0.598)$ & $(0.593)$ & & $(1.864)$ & $(1.817)$ & & $(0.797)$ & $(0.795)$ & \\
\hline \multirow[t]{2}{*}{ Large price shock $\times$ price fall $\times$ girl } & -0.896 & -1.060 & -1.132 & $-4.584^{* * *}$ & $-4.555^{* * *}$ & $-4.756^{* * *}$ & 1.098 & 0.858 & 0.853 \\
\hline & $(0.871)$ & $(0.832)$ & $(0.834)$ & $(1.656)$ & $(1.610)$ & (1.638) & $(1.200)$ & $(1.116)$ & $(1.120)$ \\
\hline \multirow[t]{2}{*}{ Medium price shock } & 0.129 & 0.057 & & -1.488 & -1.513 & & 0.149 & 0.094 & \\
\hline & $(0.331)$ & $(0.328)$ & & $(1.735)$ & $(1.687)$ & & $(0.304)$ & $(0.300)$ & \\
\hline \multirow[t]{2}{*}{ Medium price shock $\times$ girl } & 0.199 & 0.273 & 0.289 & $2.901^{* *}$ & $2.882^{* *}$ & $3.011^{* *}$ & 0.093 & 0.172 & 0.172 \\
\hline & $(0.430)$ & $(0.420)$ & $(0.424)$ & $(1.296)$ & $(1.200)$ & $(1.236)$ & $(0.421)$ & $(0.408)$ & $(0.409)$ \\
\hline \multirow[t]{2}{*}{ Medium price Shock $\times$ price fall } & 0.208 & 0.320 & & 1.308 & 1.380 & & 0.325 & 0.395 & \\
\hline & $(0.447)$ & $(0.449)$ & & $(1.823)$ & $(1.750)$ & & $(0.445)$ & $(0.439)$ & \\
\hline \multirow[t]{2}{*}{ Medium price Shock $\times$ price fall $\times$ girl } & -0.258 & -0.382 & -0.452 & -1.668 & -1.593 & -1.811 & -0.518 & -0.608 & -0.658 \\
\hline & $(0.611)$ & $(0.605)$ & $(0.611)$ & $(1.616)$ & $(1.533)$ & $(1.570)$ & $(0.626)$ & $(0.621)$ & $(0.627)$ \\
\hline Mean for girls & 4.199 & 4.199 & 4.199 & 5.096 & 5.096 & 5.096 & 3.834 & 3.834 & 3.834 \\
\hline Mean for boys & 5.047 & 5.047 & 5.047 & 6.458 & 6.458 & 6.458 & 4.483 & 4.483 & 4.483 \\
\hline \multirow[t]{2}{*}{ Marginal effect of large price shock for girls } & 0.248 & 0.220 & & $1.918^{*}$ & $1.847^{*}$ & & -0.148 & -0.141 & \\
\hline & $(0.456)$ & $(0.441)$ & & $(1.037)$ & $(1.084)$ & & $(0.615)$ & $(0.570)$ & \\
\hline \multirow[t]{2}{*}{ Marginal effect of large price fall for girls } & -0.160 & -0.173 & & 0.111 & 0.183 & & 0.301 & 0.256 & \\
\hline & $(0.355)$ & $(0.355)$ & & $(0.685)$ & $(0.679)$ & & $(0.449)$ & $(0.431)$ & \\
\hline \multirow[t]{2}{*}{ Marginal effect of large price fall for boys } & $0.848^{* *}$ & $0.878^{* *}$ & & 0.907 & 0.919 & & 0.283 & 0.296 & \\
\hline & $(0.420)$ & $(0.421)$ & & $(0.780)$ & $(0.756)$ & & $(0.589)$ & $(0.597)$ & \\
\hline \multirow[t]{2}{*}{ Marginal effect of medium price shock for girls } & 0.328 & 0.329 & & 1.413 & 1.369 & & 0.243 & 0.266 & \\
\hline & $(0.297)$ & $(0.293)$ & & $(1.021)$ & $(1.048)$ & & $(0.281)$ & $(0.278)$ & \\
\hline \multirow[t]{2}{*}{ Marginal effect of medium price fall for girls } & 0.278 & 0.267 & & 1.053 & 1.155 & & 0.050 & 0.053 & \\
\hline & $(0.286)$ & $(0.292)$ & & $(0.709)$ & $(0.699)$ & & $(0.303)$ & $(0.314)$ & \\
\hline \multirow[t]{2}{*}{ Marginal effect of medium price fall for boys } & 0.336 & 0.376 & & -0.180 & -0.133 & & 0.474 & 0.489 & \\
\hline & $(0.310)$ & $(0.315)$ & & $(0.779)$ & $(0.736)$ & & $(0.333)$ & $(0.331)$ & \\
\hline Observations & 103171 & 103171 & 103171 & 29651 & 29651 & 29651 & 73520 & 73520 & 73520 \\
\hline Time-series controls & No & Yes & Yes & No & Yes & Yes & No & Yes & Yes \\
\hline Month $\times$ year of birth fixed effects & No & No & Yes & No & No & Yes & No & $\mathrm{No}$ & Yes \\
\hline
\end{tabular}

Notes: Sample is limited to second-born children in all the regressions. The dependent variable is neonatal mortality which is equal to 0 if the child survived the first month of life and 100 if they died, so that the coefficients are in percentage changes. "Large price shock" is a dummy variable $=1$ if $\mid \Delta \mathrm{L}$ (gold price) $\mid$ is in the top quintile, "Large price shock" is a dummy variable $=1$ if $\mid \Delta \mathrm{L}$ (gold price) $\mid$ is neither in the upper quintile nor the lower quintile. "Gold price fall" is a dummy variable $=1$ if $\Delta \mathrm{L}$ (gold price) is negative, 0 otherwise. Gold prices are in USD, deflated using US CPI. All regressions control for state, year of birth and birth month fixed effects, a dummy variable =1 if the child's household was upper caste and a dummy variable for whether the child's eldest sibling was a boy. Additional "Time-series controls" include the linear and quadratic state-specific trends in month of birth; world oil price and oil price interacted with gender of the child; rainfall deviations from historical state-level mean in the month of birth, interacted with gender of the child. Standard errors are clustered by month $\times$ year of birth. 


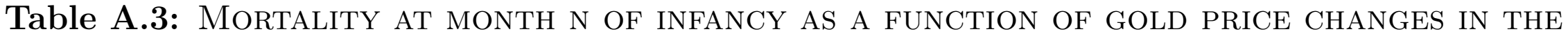
N MONTHS PRECEDING BIRTH

\begin{tabular}{|c|c|c|c|c|c|c|c|c|c|c|c|c|c|c|c|}
\hline \multirow[t]{2}{*}{ Time period: } & \multicolumn{3}{|c|}{1 month } & \multicolumn{3}{|c|}{2 months } & \multicolumn{3}{|c|}{3 months } & \multicolumn{3}{|c|}{6 months } & \multicolumn{3}{|c|}{9 months } \\
\hline & (1) & $(2)$ & (3) & $(4)$ & $(5)$ & (6) & (7) & (8) & (9) & $(10)$ & (11) & $(12)$ & $(13)$ & $(14)$ & $(15)$ \\
\hline$\Delta \mathrm{L}($ gold price $)$ & $\begin{array}{l}-4.353^{*} \\
(2.602)\end{array}$ & $\begin{array}{c}-4.403 \\
(2.704)\end{array}$ & & & & & & & & & & & & & \\
\hline$\Delta \mathrm{L}($ gold price $) \times$ girl & $\begin{array}{c}7.722^{* *} \\
(3.536)\end{array}$ & $\begin{array}{c}7.536^{* *} \\
(3.638)\end{array}$ & $\begin{array}{c}7.924^{* *} \\
(3.645)\end{array}$ & & & & & & & & & & & & \\
\hline$\Delta \mathrm{L}($ gold price $)$ & & & & $\begin{array}{c}0.647 \\
(2.457)\end{array}$ & $\begin{array}{c}0.421 \\
(2.445)\end{array}$ & & & & & & & & & & \\
\hline$\Delta \mathrm{L}($ gold price $) \times$ girl & & & & $\begin{array}{c}1.954 \\
(3.162)\end{array}$ & $\begin{array}{c}2.336 \\
(3.368)\end{array}$ & $\begin{array}{c}2.553 \\
(3.381)\end{array}$ & & & & & & & & & \\
\hline$\Delta \mathrm{L}$ (gold price) & & & & & & & $\begin{array}{c}1.136 \\
(2.351)\end{array}$ & $\begin{array}{c}0.898 \\
(2.335)\end{array}$ & & & & & & & \\
\hline$\Delta \mathrm{L}($ gold price $) \times$ girl & & & & & & & $\begin{array}{c}0.521 \\
(3.168)\end{array}$ & $\begin{array}{c}1.213 \\
(3.526)\end{array}$ & $\begin{array}{c}1.284 \\
(3.543)\end{array}$ & & & & & & \\
\hline$\Delta \mathrm{L}($ gold price $)$ & & & & & & & & & & $\begin{array}{c}2.054 \\
(1.897)\end{array}$ & $\begin{array}{c}1.586 \\
(1.944)\end{array}$ & & & & \\
\hline$\Delta \mathrm{L}($ gold price $) \times$ girl & & & & & & & & & & $\begin{array}{c}0.093 \\
(2.411)\end{array}$ & $\begin{array}{l}-0.004 \\
(2.619)\end{array}$ & $\begin{array}{l}-0.035 \\
(2.621)\end{array}$ & & & \\
\hline$\Delta \mathrm{L}($ gold price $)$ & & & & & & & & & & & & & $\begin{array}{l}2.906^{*} \\
(1.558)\end{array}$ & $\begin{array}{c}1.926 \\
(1.593)\end{array}$ & \\
\hline$\Delta \mathrm{L}($ gold price $) \times$ girl & & & & & & & & & & & & & $\begin{array}{l}-0.418 \\
(2.045) \\
\end{array}$ & $\begin{array}{l}-0.254 \\
(2.209)\end{array}$ & $\begin{array}{l}-0.315 \\
(2.192) \\
\end{array}$ \\
\hline Mean for girls & 5.096 & 5.096 & 5.096 & 5.466 & 5.466 & 5.466 & 5.893 & 5.893 & 5.893 & 6.920 & 6.920 & 6.920 & 7.808 & 7.808 & 7.808 \\
\hline Mean for boys & 6.458 & 6.458 & 6.458 & 6.973 & 6.973 & 6.973 & 7.377 & 7.377 & 7.377 & 8.250 & 8.250 & 8.250 & 8.746 & 8.746 & 8.746 \\
\hline Marginal effect for girls & $\begin{array}{c}3.369 \\
(2.571)\end{array}$ & $\begin{array}{c}3.133 \\
(2.621)\end{array}$ & & $\begin{array}{c}2.601 \\
(2.822)\end{array}$ & $\begin{array}{c}2.757 \\
(2.884)\end{array}$ & & $\begin{array}{c}1.657 \\
(2.672)\end{array}$ & $\begin{array}{c}2.110 \\
(2.823)\end{array}$ & & $\begin{array}{c}2.147 \\
(2.221)\end{array}$ & $\begin{array}{c}1.582 \\
(2.276)\end{array}$ & & $\begin{array}{c}2.489 \\
(1.855)\end{array}$ & $\begin{array}{c}1.672 \\
(1.876)\end{array}$ & \\
\hline Observations & 29651 & 29651 & 29651 & 29651 & 29651 & 29651 & 29651 & 29651 & 29651 & 29651 & 29651 & 29651 & 29651 & 29651 & 29651 \\
\hline Time-series controls & No & Yes & Yes & No & Yes & Yes & No & Yes & Yes & No & Yes & Yes & No & Yes & Yes \\
\hline Month $\times$ year of birth fixed effects & No & No & Yes & No & No & Yes & No & No & Yes & No & No & Yes & No & No & Yes \\
\hline
\end{tabular}

Notes: The dependent variable is an indicator for mortality within a given period, defined as 0 if the child survived the first 1,2,3,6 or 9 months of life in columns 1-3, 4-6, 7-9, 10-12, 13-15 respectively and 100 if they died, so that the coefficients are in percentage changes. $\Delta \mathrm{L}$ (gold price) corresponds to the change in the log average gold price during the relevant period in each column (i.e. in columns 1-3 $\Delta \mathrm{L}$ (gold price) is the change in log gold price between first month of life relative to the month before, in columns $4-6$ it is the change in the log average gold price in the first 2 months of life relative to the 2 months before etc.). Sample is limited to second-born children in all the regressions. All regressions control for state, year of birth and birth month fixed effects, a dummy variable $=1$ if the child's household was upper caste and a dummy variable for whether the child's eldest sibling was a boy. Additional Time-series controls include the linear and quadratic state-specific trends in month of birth; world oil price and oil price interacted with gender of the child; rainfall deviations from historical state-level mean in the month of birth, interacted with gender of the child. "Joint significance of lead effects" gives the p-value for the F-test that the coefficients of terms using future price changes are jointly equal to zero. 
Table A.4: Neonatal mortality as a Function of the Change in GOLD PRICES OVER The N MONTHS ENDING IN THE BIRTH MONTH

\begin{tabular}{|c|c|c|c|c|c|c|c|c|c|c|c|c|}
\hline \multirow[t]{2}{*}{ Time period: } & \multicolumn{3}{|c|}{ Month of birth } & \multicolumn{3}{|c|}{ Quarter of birth } & \multicolumn{3}{|c|}{6 months of birth } & \multicolumn{3}{|c|}{ Year of birth } \\
\hline & (1) & $(2)$ & (3) & (4) & (5) & $(6)$ & $(7)$ & $(8)$ & (9) & $(10)$ & $(11)$ & $(12)$ \\
\hline$\Delta \mathrm{L}($ gold price $)$ & $\begin{array}{l}-4.353^{*} \\
(2.602)\end{array}$ & $\begin{array}{l}-4.403 \\
(2.704)\end{array}$ & & & & & & & & & & \\
\hline$\Delta \mathrm{L}($ gold price $) \times \operatorname{girl}$ & $\begin{array}{c}7.722^{* *} \\
(3.536)\end{array}$ & $\begin{array}{c}7.536^{* *} \\
(3.638)\end{array}$ & $\begin{array}{l}7.924^{* *} \\
(3.645)\end{array}$ & & & & & & & & & \\
\hline$\Delta \mathrm{L}($ gold price $)$ & & & & $\begin{array}{l}-1.062 \\
(2.178)\end{array}$ & $\begin{array}{c}-2.651 \\
(2.273)\end{array}$ & & & & & & & \\
\hline$\Delta \mathrm{L}($ gold price $) \times$ girl & & & & $\begin{array}{c}3.611 \\
(3.178)\end{array}$ & $\begin{array}{l}5.727^{*} \\
(3.431)\end{array}$ & $\begin{array}{l}5.792^{*} \\
(3.460)\end{array}$ & & & & & & \\
\hline$\Delta \mathrm{L}($ gold price $)$ & & & & & & & $\begin{array}{c}1.612 \\
(1.517)\end{array}$ & $\begin{array}{c}0.771 \\
(1.684)\end{array}$ & & & & \\
\hline$\Delta \mathrm{L}($ gold price $) \times$ girl & & & & & & & $\begin{array}{c}2.060 \\
(1.709)\end{array}$ & $\begin{array}{c}2.351 \\
(1.973)\end{array}$ & $\begin{array}{c}2.432 \\
(1.971)\end{array}$ & & & \\
\hline$\Delta \mathrm{L}($ gold price $)$ & & & & & & & & & & $\begin{array}{c}1.523 \\
(1.317)\end{array}$ & $\begin{array}{c}1.009 \\
(1.376)\end{array}$ & \\
\hline$\Delta \mathrm{L}($ gold price $) \times$ girl & & & & & & & & & & $\begin{array}{c}1.874 \\
(1.380) \\
\end{array}$ & $\begin{array}{c}2.568 \\
(1.814) \\
\end{array}$ & $\begin{array}{c}2.642 \\
(1.820) \\
\end{array}$ \\
\hline Mean for girls & 5.096 & 5.096 & 5.096 & 5.096 & 5.096 & 5.096 & 5.096 & 5.096 & 5.096 & 5.096 & 5.096 & 5.096 \\
\hline Mean for boys & 6.458 & 6.458 & 6.458 & 6.458 & 6.458 & 6.458 & 6.458 & 6.458 & 6.458 & 6.458 & 6.458 & 6.458 \\
\hline Marginal effect for girls & $\begin{array}{c}3.369 \\
(2.571)\end{array}$ & $\begin{array}{c}3.133 \\
(2.621)\end{array}$ & & $\begin{array}{c}2.549 \\
(2.644)\end{array}$ & $\begin{array}{c}3.076 \\
(2.721)\end{array}$ & & $\begin{array}{c}3.672^{* *} \\
(1.672)\end{array}$ & $\begin{array}{l}3.122^{*} \\
(1.853)\end{array}$ & & $\begin{array}{c}3.396^{* *} \\
(1.343)\end{array}$ & $\begin{array}{c}3.577^{* *} \\
(1.436)\end{array}$ & \\
\hline Observations & 29651 & 29651 & 29651 & 29651 & 29651 & 29651 & 29651 & 29651 & 29651 & 29651 & 29651 & 29651 \\
\hline Time-series controls & No & Yes & Yes & No & Yes & Yes & No & Yes & Yes & No & Yes & Yes \\
\hline Month $\times$ year of birth fixed effects & No & No & Yes & No & No & Yes & No & No & Yes & No & No & Yes \\
\hline
\end{tabular}

Notes: The dependent variable is neonatal mortality which is equal to 0 if the child survived the first month of life and 100 if they died, so that the coefficients are in percentage changes. Sample is limited to second-born children born before 1985 in all the regressions. In columns 1-3, $\Delta \mathrm{L}$ (gold price) is the change in log of the monthly gold price in the month of birth of the child, relative to the previous month; in columns 4-6, $\Delta \mathrm{L}$ (gold price) is the change in log of the average gold price 3 months before birth of the child, relative to the previous 3 months; in columns 7-9, $\Delta \mathrm{L}$ (gold price) is the change in log of the average gold price 6 months before birth of the child, relative to the previous 6 months; in columns 10-12, $\Delta \mathrm{L}$ (gold price) is the change in log of the average gold price 12 months before birth of the child, relative to the previous 12 months. Gold prices are in USD, deflated using US CPI. All regressions control for state, year of birth and birth month fixed effects, a dummy variable $=1$ if the child's household was upper caste and a dummy variable for whether the child's eldest sibling was a boy : Additional "Time-series controls" include the linear and quadratic state-specific trend w world oil price and oil price interacted with gender of the child; rainfall deviations from historical state-level mean in the month of birth, interacted with gender of the child Standard errors are clustered by month $\times$ year of birth. 
Table A.5: Neonatal mortality: Heterogeneity by Region

\begin{tabular}{|c|c|c|c|c|c|c|c|c|c|}
\hline \multirow[t]{2}{*}{ Sample: } & \multicolumn{3}{|c|}{ All states } & \multicolumn{3}{|c|}{ Southern states } & \multicolumn{3}{|c|}{ Northern (BIMARU) states } \\
\hline & (1) & $(2)$ & $(3)$ & (4) & $(5)$ & (6) & (7) & (8) & (9) \\
\hline \multirow[t]{2}{*}{$\Delta \mathrm{L}($ gold price $)$} & $-4.353^{*}$ & -4.403 & & -6.038 & -4.077 & & -2.821 & -3.096 & \\
\hline & $(2.602)$ & $(2.704)$ & & $(5.850)$ & $(5.742)$ & & $(5.354)$ & $(5.433)$ & \\
\hline \multirow[t]{2}{*}{$\Delta \mathrm{L}($ gold price $) \times$ girl } & $7.722^{* *}$ & $7.536^{* *}$ & $7.924^{* *}$ & 0.382 & -2.588 & -2.556 & 9.642 & 8.307 & 8.185 \\
\hline & $(3.536)$ & $(3.638)$ & $(3.645)$ & $(9.267)$ & $(9.141)$ & $(9.211)$ & $(8.314)$ & $(8.197)$ & $(8.247)$ \\
\hline Mean for girls & 5.096 & 5.096 & 5.096 & 3.880 & 3.880 & 3.880 & 6.660 & 6.660 & 6.660 \\
\hline Mean for boys & 6.458 & 6.458 & 6.458 & 5.575 & 5.575 & 5.575 & 7.505 & 7.505 & 7.505 \\
\hline \multirow[t]{2}{*}{ Marginal effect for girls } & 3.369 & 3.133 & & -5.656 & -6.665 & & 6.821 & 5.211 & \\
\hline & $(2.571)$ & $(2.621)$ & & $(6.145)$ & $(6.157)$ & & $(6.318)$ & $(6.392)$ & \\
\hline Observations & 29651 & 29651 & 29651 & 5592 & 5592 & 5592 & 11231 & 11231 & 11231 \\
\hline Time-series controls & No & Yes & Yes & No & Yes & Yes & No & Yes & Yes \\
\hline Month $\times$ year of birth fixed effects & No & No & Yes & No & No & Yes & No & No & Yes \\
\hline
\end{tabular}

Notes: The dependent variable is neonatal mortality which is equal to 0 if the child survived the first month of life and 100 if they died, so that the coefficients are in percentage changes. Sample is limited to second-born children born before 1985 in all the regressions. The sample is restricted to the Southern states (Andhra Pradesh. Telangana, Karnataka, Kerala and Tamil Nadu) in columns 4-6; Northern or BIMARU states (Bihar, Jharkhand, Madhya Pradesh, Chhattisgarh, Rajasthan and Uttar Pradesh) in columns 7-9. $\Delta$ L(gold price) is the change in log of the monthly gold price in the month of birth of the child, relative to the previous month. Gold prices are in USD, deflated using US CPI. All regressions control for state, year of birth and birth month fixed effects, a dummy variable $=1$ if the child's household was upper caste and a dummy variable for whether the child's eldest sibling was a boy. Additional "Time-series controls" include the linear and quadratic state-specific trends in month of birth; world oil price and oil price interacted with gender of the child; rainfall deviations from historical state-level mean in the month of birth, interacted with gender of the child. Standard errors are clustered by month $\times$ year of birth. 
Table A.6: Change in Neonatal Mortality Rate

\begin{tabular}{|c|c|c|c|c|c|c|c|c|}
\hline \multirow[t]{2}{*}{ Time period: } & \multicolumn{2}{|c|}{$1972-2005$} & \multicolumn{2}{|c|}{ Pre-1985 } & \multicolumn{2}{|c|}{ Post-1985 } & \multicolumn{2}{|c|}{ 1972-2005: Interactions } \\
\hline & $(1)$ & $(2)$ & $(3)$ & (4) & $(5)$ & $(6)$ & $(7)$ & $(8)$ \\
\hline$\Delta \mathrm{L}($ gold price $)$ & $\begin{array}{c}-16.372^{* * *} \\
(4.481)\end{array}$ & $\begin{array}{c}-17.529 * * * \\
(4.634)\end{array}$ & $\begin{array}{c}-20.270^{* * *} \\
(5.583)\end{array}$ & $\begin{array}{c}-22.102^{* * *} \\
(5.874)\end{array}$ & $\begin{array}{l}-6.092 \\
(5.988)\end{array}$ & $\begin{array}{l}-6.954 \\
(6.223)\end{array}$ & $\begin{array}{c}-19.633^{* * *} \\
(5.672)\end{array}$ & $\begin{array}{c}-20.519 * * * \\
(5.787)\end{array}$ \\
\hline$\Delta \mathrm{L}($ gold price $) \times$ girl & $\begin{array}{c}17.013^{* *} \\
(6.930)\end{array}$ & $\begin{array}{c}18.257^{* *} \\
(7.095)\end{array}$ & $\begin{array}{c}23.099 * * * \\
(8.264)\end{array}$ & $\begin{array}{c}24.443^{* * * *} \\
(8.832)\end{array}$ & $\begin{array}{c}-1.495 \\
(12.375)\end{array}$ & $\begin{array}{c}-0.014 \\
(12.268)\end{array}$ & $\begin{array}{c}22.946^{* * * *} \\
(8.227)\end{array}$ & $\begin{array}{c}23.895^{* * *} \\
(8.429)\end{array}$ \\
\hline$\Delta \mathrm{L}($ gold price $) \times$ post -1985 & & & & & & & $\begin{array}{l}13.531 \\
(8.325)\end{array}$ & $\begin{array}{l}12.548 \\
(8.333)\end{array}$ \\
\hline$\Delta \mathrm{L}($ gold price $) \times$ post- $1985 \times$ girl & & & & & & & $\begin{array}{l}-24.433 \\
(14.844)\end{array}$ & $\begin{array}{l}-23.545 \\
(14.827)\end{array}$ \\
\hline Mean for girls & -0.038 & -0.038 & -0.091 & -0.091 & -0.009 & -0.009 & -0.038 & -0.038 \\
\hline Mean for boys & -0.073 & -0.073 & -0.128 & -0.128 & -0.043 & -0.043 & -0.073 & -0.073 \\
\hline Marginal effect for girls & $\begin{array}{c}0.642 \\
(4.992)\end{array}$ & $\begin{array}{c}0.727 \\
(4.980)\end{array}$ & $\begin{array}{c}2.829 \\
(5.813)\end{array}$ & $\begin{array}{c}2.340 \\
(5.959)\end{array}$ & $\begin{array}{l}-7.587 \\
(9.575)\end{array}$ & $\begin{array}{l}-6.968 \\
(9.358)\end{array}$ & $\begin{array}{c}3.313 \\
(5.706)\end{array}$ & $\begin{array}{c}3.377 \\
(5.711)\end{array}$ \\
\hline Marginal effect for boys post-1985 & & & & & & & $\begin{array}{l}-6.102 \\
(6.061)\end{array}$ & $\begin{array}{l}-7.971 \\
(6.204)\end{array}$ \\
\hline Marginal effect for girls post- 1985 & & & & & & & $\begin{array}{l}-7.589 \\
(9.409)\end{array}$ & $\begin{array}{l}-7.621 \\
(9.379)\end{array}$ \\
\hline Observations & 15830 & 15830 & 5633 & 5633 & 10197 & 10197 & 15830 & 15830 \\
\hline Time-series controls & No & Yes & No & Yes & No & Yes & No & Yes \\
\hline
\end{tabular}

Notes: The table shows results of estimating specification 2 where the dependent variable is change in the neonatal mortality rate at the state $\times$ gender level in month $t$. Sample is limited to second-born children in all the regressions. All regressions control for state and birth month fixed effects. Additional "Time-series controls" include the linear and quadratic state-specific trends in month of birth; world oil price and oil price interacted with gender; rainfall deviations from historical state-level mean in the month of birth, interacted with gender of the child. In columns (10)-(12), the "Marginal effect for girls" provides the marginal effect pre-1985. Standard errors are clustered by month $\times$ year of birth. 
Table A.7: Neonatal Mortality: Showing Oil Price and Rain Coefficients

\begin{tabular}{|c|c|c|c|c|c|c|c|c|c|c|c|c|}
\hline \multirow[t]{2}{*}{ Time period: } & \multicolumn{3}{|c|}{ 1972-2005 } & \multicolumn{3}{|c|}{ Pre-1985 } & \multicolumn{3}{|c|}{ Post-1985 } & \multicolumn{3}{|c|}{$1972-2005$} \\
\hline & $(1)$ & $(2)$ & $(3)$ & $(4)$ & $(5)$ & $(6)$ & $(7)$ & $(8)$ & $(9)$ & $(10)$ & $(11)$ & $(12)$ \\
\hline \multirow[t]{2}{*}{$\Delta \mathrm{L}$ (gold price $)$} & -3.446 & $-3.911^{*}$ & & $-4.353^{*}$ & -4.403 & & -3.856 & -5.020 & & -3.581 & -3.630 & \\
\hline & $(2.344)$ & $(2.350)$ & & $(2.602)$ & $(2.704)$ & & $(4.136)$ & $(4.139)$ & & $(2.732)$ & $(2.706)$ & \\
\hline \multirow[t]{2}{*}{$\Delta \mathrm{L}($ gold price $) \times$ girl } & $5.410^{*}$ & $5.812^{*}$ & $6.081^{* *}$ & $7.722^{* *}$ & $7.536^{* *}$ & $7.924^{* *}$ & 0.370 & 1.496 & 1.469 & $7.816^{* *}$ & $7.905^{* *}$ & $8.326^{* *}$ \\
\hline & $(3.108)$ & $(3.056)$ & $(3.060)$ & $(3.536)$ & $(3.638)$ & $(3.645)$ & $(5.949)$ & $(5.643)$ & $(5.642)$ & $(3.551)$ & $(3.535)$ & $(3.553)$ \\
\hline \multirow[t]{2}{*}{$\Delta \mathrm{L}$ (oil price) } & & 1.478 & & & 2.776 & & & 1.449 & & & 1.540 & \\
\hline & & $(1.103)$ & & & $(2.240)$ & & & $(1.219)$ & & & $(1.097)$ & \\
\hline \multirow[t]{2}{*}{$\Delta \mathrm{L}($ oil price $) \times$ girl } & & -1.895 & -1.912 & & -1.147 & -1.250 & & -1.811 & -1.853 & & -1.751 & -1.756 \\
\hline & & $(1.666)$ & $(1.696)$ & & $(3.428)$ & $(3.530)$ & & $(1.834)$ & $(1.849)$ & & $(1.639)$ & $(1.666)$ \\
\hline \multirow[t]{2}{*}{ rainfall shock } & & -0.050 & -0.044 & & -0.002 & 0.012 & & -0.056 & -0.051 & & -0.051 & -0.045 \\
\hline & & $(0.056)$ & $(0.058)$ & & $(0.136)$ & $(0.147)$ & & $(0.063)$ & $(0.065)$ & & $(0.056)$ & $(0.058)$ \\
\hline \multirow[t]{2}{*}{ rainfall shock $\times$ girl } & & -0.058 & -0.062 & & $-0.283^{*}$ & $-0.288^{*}$ & & 0.011 & 0.006 & & -0.057 & -0.061 \\
\hline & & $(0.070)$ & $(0.070)$ & & $(0.163)$ & $(0.163)$ & & $(0.075)$ & $(0.075)$ & & $(0.070)$ & $(0.070)$ \\
\hline \multirow{2}{*}{$\Delta \mathrm{L}($ gold price $) \times$ post -1985} & & & & & & & & & & 0.316 & -1.042 & \\
\hline & & & & & & & & & & $(4.982)$ & $(4.955)$ & \\
\hline \multirow[t]{2}{*}{$\Delta \mathrm{L}($ gold price $) \times$ post $-1985 \times$ girl } & & & & & & & & & & -7.387 & -6.529 & -7.070 \\
\hline & & & & & & & & & & $(6.884)$ & $(6.625)$ & $(6.640)$ \\
\hline Observations & 103171 & 103171 & 103171 & 29651 & 29651 & 29651 & 73520 & 73520 & 73520 & 103171 & 103171 & 103171 \\
\hline Time-series controls & No & Yes & Yes & No & Yes & Yes & No & Yes & Yes & No & Yes & Yes \\
\hline Month $\times$ year of birth fixed effects & No & No & Yes & No & No & Yes & No & No & Yes & No & No & Yes \\
\hline
\end{tabular}

Notes: This is Table 3 with time series controls displayed. Please refer to footnote of Table 3 for further details. 
Table A.8: Placebo Test: Neonatal Mortality, with Leads of Price

\begin{tabular}{|c|c|c|c|c|c|c|c|c|c|}
\hline & $(1)$ & $(2)$ & $(3)$ & $(4)$ & $(5)$ & $(6)$ & $(7)$ & $(8)$ & $(9)$ \\
\hline$\Delta \mathrm{L}$ (gold price) & $\begin{array}{l}-3.181 \\
(2.353)\end{array}$ & $\begin{array}{c}-3.608 \\
(2.363)\end{array}$ & & $\begin{array}{l}-3.490 \\
(2.344)\end{array}$ & $\begin{array}{c}-3.902^{*} \\
(2.352)\end{array}$ & & $\begin{array}{c}-3.652 \\
(2.335)\end{array}$ & $\begin{array}{c}-4.087^{*} \\
(2.325)\end{array}$ & \\
\hline$\Delta \mathrm{L}($ gold price $) \times$ girl & $\begin{array}{l}5.416^{*} \\
(3.106)\end{array}$ & $\begin{array}{l}5.794^{*} \\
(3.056)\end{array}$ & $\begin{array}{c}6.057^{* *} \\
(3.064)\end{array}$ & $\begin{array}{l}5.420^{*} \\
(3.121)\end{array}$ & $\begin{array}{l}5.795^{*} \\
(3.074)\end{array}$ & $\begin{array}{l}6.033^{*} \\
(3.084)\end{array}$ & $\begin{array}{l}5.437^{*} \\
(3.126)\end{array}$ & $\begin{array}{l}5.811^{*} \\
(3.081)\end{array}$ & $\begin{array}{l}6.050^{*} \\
(3.090)\end{array}$ \\
\hline$\Delta \mathrm{L}($ gold price $)$ at $(\mathrm{t}+1)$ & $\begin{array}{c}3.392 \\
(2.536)\end{array}$ & $\begin{array}{c}3.274 \\
(2.556)\end{array}$ & & $\begin{array}{c}3.078 \\
(2.520)\end{array}$ & $\begin{array}{c}2.967 \\
(2.531)\end{array}$ & & $\begin{array}{c}2.848 \\
(2.532)\end{array}$ & $\begin{array}{c}2.706 \\
(2.528)\end{array}$ & \\
\hline$\Delta \mathrm{L}($ gold price $)$ at $(\mathrm{t}+1) \times \operatorname{girl}$ & $\begin{array}{l}-2.107 \\
(3.944)\end{array}$ & $\begin{array}{l}-1.751 \\
(3.846)\end{array}$ & $\begin{array}{c}-1.386 \\
(3.850)\end{array}$ & $\begin{array}{c}-2.101 \\
(3.957)\end{array}$ & $\begin{array}{c}-1.745 \\
(3.860)\end{array}$ & $\begin{array}{l}-1.390 \\
(3.862)\end{array}$ & $\begin{array}{c}-2.062 \\
(3.955)\end{array}$ & $\begin{array}{l}-1.707 \\
(3.858)\end{array}$ & $\begin{array}{c}-1.354 \\
(3.860)\end{array}$ \\
\hline$\Delta \mathrm{L}($ gold price $)$ at $(\mathrm{t}+2)$ & & & & $\begin{array}{l}-1.565 \\
(2.399)\end{array}$ & $\begin{array}{l}-1.460 \\
(2.389)\end{array}$ & & $\begin{array}{l}-1.755 \\
(2.434)\end{array}$ & $\begin{array}{l}-1.682 \\
(2.425)\end{array}$ & \\
\hline$\Delta \mathrm{L}($ gold price $)$ at $(\mathrm{t}+2) \times$ girl & & & & $\begin{array}{l}-0.516 \\
(3.590)\end{array}$ & $\begin{array}{c}-0.708 \\
(3.594)\end{array}$ & $\begin{array}{l}-0.655 \\
(3.597)\end{array}$ & $\begin{array}{c}-0.502 \\
(3.594)\end{array}$ & $\begin{array}{l}-0.696 \\
(3.597)\end{array}$ & $\begin{array}{l}-0.636 \\
(3.600)\end{array}$ \\
\hline$\Delta \mathrm{L}$ (gold price) at $(\mathrm{t}+3)$ & & & & & & & $\begin{array}{l}-1.450 \\
(2.710)\end{array}$ & $\begin{array}{l}-1.578 \\
(2.771)\end{array}$ & \\
\hline$\Delta \mathrm{L}($ gold price $)$ at $(\mathrm{t}+3) \times$ girl & & & & & & & $\begin{array}{c}0.901 \\
(3.597)\end{array}$ & $\begin{array}{c}0.812 \\
(3.601)\end{array}$ & $\begin{array}{c}1.046 \\
(3.591)\end{array}$ \\
\hline Joint significance of lead effects & 0.386 & 0.407 & $\mathrm{n} / \mathrm{a}$ & 0.573 & 0.599 & 0.931 & 0.780 & 0.801 & 0.974 \\
\hline Observations & 103171 & 103171 & 103171 & 103171 & 103171 & 103171 & 103171 & 103171 & 103171 \\
\hline Time-series controls & No & Yes & Yes & No & Yes & Yes & No & Yes & Yes \\
\hline Month $\times$ year of birth fixed effects & No & No & Yes & No & No & Yes & No & No & Yes \\
\hline
\end{tabular}

Notes: The dependent variable is an indicator for neonatal mortality, defined as 0 if the child survived the first month of life and 100 if they died, so that the coefficients are in percentage changes. Sample is limited to second-born children in all the regressions. All regressions control for state, year of birth and birth month fixed effects, a dummy variable $=1$ if the child's household was upper caste and a dummy variable for whether the child's eldest sibling was a boy. Additional Time-series controls include the linear and quadratic state-specific trends in month of birt, world oil price and oil price interacted with gender of the child, rainfall deviations from historical state-level mean in the month of birth, interacted with gender of the child. "Joint significance of lead effects" gives the p-value for the
F-test that the coefficients of terms using future price changes are jointly equal to zero. 
Table A.9: Neonatal Mortality, by Religion

\begin{tabular}{lcccccc}
\hline \hline Sample: & \multicolumn{3}{c}{ Hindus } & \multicolumn{3}{c}{ Non-Hindus } \\
\hline & $(1)$ & $(2)$ & $(3)$ & $(4)$ & $(5)$ & $(6)$ \\
\hline$\Delta$ L(gold price) & -3.446 & $-3.911^{*}$ & & 4.007 & 4.383 & \\
& $(2.344)$ & $(2.350)$ & & $(4.003)$ & $(4.127)$ & \\
$\Delta$ L(gold price) $\times$ girl & $5.410^{*}$ & $5.812^{*}$ & $6.081^{* *}$ & -2.020 & -3.040 & -2.808 \\
& $(3.108)$ & $(3.056)$ & $(3.060)$ & $(4.845)$ & $(4.970)$ & $(5.056)$ \\
\hline Mean for girls & 4.199 & 4.199 & 4.199 & 2.856 & 2.856 & 2.856 \\
Mean for boys & 5.047 & 5.047 & 5.047 & 3.684 & 3.684 & 3.684 \\
Marginal effect for girls & 1.964 & 1.901 & & 1.987 & 1.343 & \\
& $(2.057)$ & $(2.034)$ & & $(3.515)$ & $(3.613)$ & \\
Observations & 103171 & 103171 & 103171 & 34263 & 34263 & 34263 \\
Time-series controls & No & Yes & Yes & No & Yes & Yes \\
Month $\times$ year of birth fixed effects & No & No & Yes & No & No & Yes \\
\hline \hline
\end{tabular}

Notes: The dependent variable is neonatal mortality which is equal to 0 if the child survived the first month of life and 100 if they died, so that the coefficients are in percentage changes. The sample is restricted to second-born children born in Hindu families in columns (1)-(3) and in Muslims families in columns (4)-(6). All regressions control for state, year of birth and birth month fixed effects and a dummy variable for whether the child's eldest sibling was a boy. Additional Time-series controls include the linear and quadratic state-specific trends in month of birth; world oil price and oil price interacted with gender of the child; rainfall deviations from historical state-level mean in the month of birth, interacted with gender of the child. In columns (1)-(3) regressions also control for a dummy variable $=1$ if the child's household was upper caste. 
Table A.10: Sex Ratio at Birth, By Religion

\begin{tabular}{lcccc}
\hline \hline Sample: & \multicolumn{2}{c}{ Hindus } & \multicolumn{2}{c}{ Non-Hindus } \\
\hline & $(1)$ & $(2)$ & $(3)$ & $(4)$ \\
\hline$\Delta$ L(gold price) & -8.739 & $-12.147^{* *}$ & 5.007 & 7.369 \\
& $(6.079)$ & $(6.056)$ & $(11.769)$ & $(12.076)$ \\
\hline Sample mean & 47.750 & 47.750 & 48.223 & 48.223 \\
Observations & 73520 & 73520 & 25575 & 25575 \\
Time-series controls & No & Yes & No & Yes \\
\hline \hline
\end{tabular}

Notes: The dependent variable is an indicator for the gender of the child being a girl, multiplied by 100. Sample is limited to second-born children born after 1985 in all the regressions. All regressions control for state, year of birth and birth month fixed effects, a dummy variable $=1$ if the child's household was upper caste and a dummy variable for whether the child's eldest sibling was a boy. Additional Timeseries controls include the linear and quadratic state-specific trends in month of birth; world oil price; rainfall deviations from historical state-level mean in the month of birth,and their lags up to 12 months before birth. 
Table A.11: Neonatal Mortality, Excluding Peak of Gold Prices

\begin{tabular}{|c|c|c|c|c|c|c|c|c|c|c|c|c|}
\hline \multirow{2}{*}{ Time period: } & \multicolumn{3}{|c|}{ 1972-2005 } & \multicolumn{3}{|c|}{ Pre-1985 } & \multicolumn{3}{|c|}{ Post-1985 } & \multicolumn{3}{|c|}{ 1972-2005: Interactions } \\
\hline & $(1)$ & $(2)$ & $(3)$ & $(4)$ & $(5)$ & $(6)$ & $(7)$ & $(8)$ & $(9)$ & $(10)$ & $(11)$ & $(12)$ \\
\hline$\Delta \mathrm{L}($ gold price $)$ & $\begin{array}{c}-4.760^{* *} \\
(2.369)\end{array}$ & $\begin{array}{c}-5.301^{* *} \\
(2.379)\end{array}$ & & $\begin{array}{c}-6.049^{* *} \\
(2.749)\end{array}$ & $\begin{array}{c}-6.454^{* *} \\
(2.882)\end{array}$ & & $\begin{array}{l}-3.856 \\
(4.136)\end{array}$ & $\begin{array}{l}-5.020 \\
(4.139)\end{array}$ & & $\begin{array}{l}-5.387^{*} \\
(2.801)\end{array}$ & $\begin{array}{l}-5.388^{*} \\
(2.809)\end{array}$ & \\
\hline$\Delta \mathrm{L}($ gold price $) \times \operatorname{girl}$ & $\begin{array}{l}5.534^{*} \\
(3.307)\end{array}$ & $\begin{array}{l}6.041^{*} \\
(3.254)\end{array}$ & $\begin{array}{l}6.114^{*} \\
(3.261)\end{array}$ & $\begin{array}{l}7.718^{* *} \\
(3.877)\end{array}$ & $\begin{array}{l}7.886^{*} \\
(4.042)\end{array}$ & $\begin{array}{l}8.031^{* *} \\
(4.040)\end{array}$ & $\begin{array}{c}0.370 \\
(5.949)\end{array}$ & $\begin{array}{l}1.496 \\
(5.643)\end{array}$ & $\begin{array}{l}1.469 \\
(5.642)\end{array}$ & $\begin{array}{l}7.893^{* *} \\
(3.884)\end{array}$ & $\begin{array}{l}8.038^{* *} \\
(3.881)\end{array}$ & $\begin{array}{c}8.238^{* *} \\
(3.899)\end{array}$ \\
\hline$\Delta \mathrm{L}($ gold price $) \times$ post -1985 & & & & & & & & & & $\begin{array}{l}2.115 \\
(5.016)\end{array}$ & $\begin{array}{c}0.548 \\
(5.023)\end{array}$ & \\
\hline$\Delta \mathrm{L}($ gold price $) \times$ post $-1985 \times$ girl & & & & & & & & & & $\begin{array}{l}-7.452 \\
(7.064)\end{array}$ & $\begin{array}{l}-6.547 \\
(6.803)\end{array}$ & $\begin{array}{l}-6.890 \\
(6.821)\end{array}$ \\
\hline Mean for girls & 4.176 & 4.176 & 4.176 & 5.029 & 5.029 & 5.029 & 3.834 & 3.834 & 3.834 & 4.176 & 4.176 & 4.176 \\
\hline Mean for boys & 5.032 & 5.032 & 5.032 & 6.433 & 6.433 & 6.433 & 4.483 & 4.483 & 4.483 & 5.032 & 5.032 & 5.032 \\
\hline Marginal effect for girls & $\begin{array}{c}0.774 \\
(2.111)\end{array}$ & $\begin{array}{c}0.740 \\
(2.076)\end{array}$ & & $\begin{array}{l}1.669 \\
(2.720)\end{array}$ & $\begin{array}{l}1.433 \\
(2.788)\end{array}$ & & $\begin{array}{l}-3.485 \\
(3.463)\end{array}$ & $\begin{array}{l}-3.524 \\
(3.242)\end{array}$ & & $\begin{array}{l}2.506 \\
(2.549)\end{array}$ & $\begin{array}{c}2.650 \\
(2.552)\end{array}$ & \\
\hline Marginal effect for boys post-1985 & & & & & & & & & & $\begin{array}{l}-3.272 \\
(4.191)\end{array}$ & $\begin{array}{l}-4.840 \\
(4.214)\end{array}$ & \\
\hline Marginal effect for girls post-1985 & & & & & & & & & & $\begin{array}{l}-2.831 \\
(3.560)\end{array}$ & $\begin{array}{l}-3.349 \\
(3.393)\end{array}$ & $\begin{array}{c}1.348 \\
(5.633)\end{array}$ \\
\hline Observations & 102661 & 102661 & 102661 & 29141 & 29141 & 29141 & 73520 & 73520 & 73520 & 102661 & 102661 & 102661 \\
\hline Time-series controls & No & Yes & Yes & No & Yes & Yes & No & Yes & Yes & No & Yes & Yes \\
\hline Month $\times$ year of birth fixed effects & No & No & Yes & No & No & Yes & No & No & Yes & No & No & Yes \\
\hline
\end{tabular}

Notes: The sample excludes children born between 1 November 1979 and 1 February 1980 . The dependent variable is neonatal mortality which is equal to 0 if the child survived the first month of life and 100 if they died, so that the coeffients are in percentage changes. Sample is limited to second-born children in all the regressions. All regressions control for state, year of birth and birth month fixed effects, a dummy variable $=1$ if the child's household was upper caste and a dummy variable for whether the child's eldest sibling was a boy. Additional Time-series controls include the linear and quadratic state-specific trends in month of birth; world oil price and oil price interacted with gender of the child; rainfall deviations from historical state-level mean in the month of birth, interacted with gender of the child. In columns (10)-(12), the "Marginal effect for girls" provides the marginal effect pre-1985. 
Table A.12: Neonatal Mortality: By Wealth

\begin{tabular}{|c|c|c|c|c|c|c|c|c|c|}
\hline & \multicolumn{3}{|c|}{ Full sample } & \multicolumn{3}{|c|}{ Poor } & \multicolumn{3}{|c|}{ Wealthy } \\
\hline & (1) & (2) & (3) & (4) & $(5)$ & (6) & (7) & (8) & (9) \\
\hline$\Delta \mathrm{L}($ gold price $)$ & $\begin{array}{l}-3.581 \\
(2.732)\end{array}$ & $\begin{array}{l}-3.630 \\
(2.706)\end{array}$ & & $\begin{array}{c}-8.258^{* *} \\
(4.067)\end{array}$ & $\begin{array}{c}-8.610^{* *} \\
(4.033)\end{array}$ & & $\begin{array}{c}2.961 \\
(3.680)\end{array}$ & $\begin{array}{c}3.172 \\
(3.600)\end{array}$ & \\
\hline$\Delta \mathrm{L}($ gold price $) \times \operatorname{girl}$ & $\begin{array}{l}7.816^{* *} \\
(3.551)\end{array}$ & $\begin{array}{l}7.905^{* *} \\
(3.535)\end{array}$ & $\begin{array}{c}8.326^{* *} \\
(3.553)\end{array}$ & $\begin{array}{c}12.236^{* *} \\
(5.197)\end{array}$ & $\begin{array}{c}12.432^{* *} \\
(4.981)\end{array}$ & $\begin{array}{c}13.051^{* * *} \\
(4.909)\end{array}$ & $\begin{array}{l}1.708 \\
(5.933)\end{array}$ & $\begin{array}{c}2.072 \\
(5.882)\end{array}$ & $\begin{array}{c}2.520 \\
(5.983)\end{array}$ \\
\hline$\Delta \mathrm{L}($ gold price $) \times$ post -1985 & $\begin{array}{c}0.316 \\
(4.982)\end{array}$ & $\begin{array}{l}-1.042 \\
(4.955)\end{array}$ & & $\begin{array}{c}3.900 \\
(7.390)\end{array}$ & $\begin{array}{c}2.868 \\
(7.443)\end{array}$ & & $\begin{array}{l}-4.227 \\
(6.278)\end{array}$ & $\begin{array}{l}-5.887 \\
(6.382)\end{array}$ & \\
\hline$\Delta \mathrm{L}($ gold price $) \times$ post $-1985 \times$ girl & $\begin{array}{l}-7.387 \\
(6.884)\end{array}$ & $\begin{array}{l}-6.529 \\
(6.625)\end{array}$ & $\begin{array}{l}-7.070 \\
(6.640)\end{array}$ & $\begin{array}{c}-9.047 \\
(11.017)\end{array}$ & $\begin{array}{c}-7.552 \\
(10.633)\end{array}$ & $\begin{array}{c}-7.833 \\
(10.570)\end{array}$ & $\begin{array}{l}-5.863 \\
(8.339)\end{array}$ & $\begin{array}{l}-5.925 \\
(8.721)\end{array}$ & $\begin{array}{l}-5.500 \\
(8.905)\end{array}$ \\
\hline Mean for girls & 4.199 & 4.199 & 4.199 & 5.089 & 5.089 & 5.089 & 2.929 & 2.929 & 2.929 \\
\hline Mean for boys & 5.047 & 5.047 & 5.047 & 6.249 & 6.249 & 6.249 & 3.399 & 3.399 & 3.399 \\
\hline Marginal effect for girls & $\begin{array}{l}4.235^{*} \\
(2.461)\end{array}$ & $\begin{array}{l}4.276^{*} \\
(2.461)\end{array}$ & & $\begin{array}{c}3.977 \\
(4.113)\end{array}$ & $\begin{array}{c}3.823 \\
(3.972)\end{array}$ & & $\begin{array}{c}4.670 \\
(4.136)\end{array}$ & $\begin{array}{c}5.243 \\
(4.141)\end{array}$ & \\
\hline Marginal effect for boys post- 1985 & $\begin{array}{l}-3.265 \\
(4.191)\end{array}$ & $\begin{array}{l}-4.672 \\
(4.210)\end{array}$ & & $\begin{array}{l}-4.358 \\
(6.240)\end{array}$ & $\begin{array}{l}-5.742 \\
(6.305)\end{array}$ & & $\begin{array}{l}-1.265 \\
(5.058)\end{array}$ & $\begin{array}{l}-2.716 \\
(5.295)\end{array}$ & \\
\hline Marginal effect for girls post- 1985 & $\begin{array}{l}-2.836 \\
(3.550)\end{array}$ & $\begin{array}{l}-3.296 \\
(3.396)\end{array}$ & $\begin{array}{c}1.256 \\
(5.635)\end{array}$ & $\begin{array}{l}-1.170 \\
(6.034)\end{array}$ & $\begin{array}{l}-0.861 \\
(5.811)\end{array}$ & $\begin{array}{l}5.217 \\
(9.310)\end{array}$ & $\begin{array}{l}-5.420 \\
(4.786)\end{array}$ & $\begin{array}{l}-6.570 \\
(5.041)\end{array}$ & $\begin{array}{l}-2.980 \\
(6.501)\end{array}$ \\
\hline Observations & 103171 & 103171 & 103171 & 60137 & 60137 & 60137 & 43034 & 43034 & 43034 \\
\hline Time-series controls & No & Yes & Yes & No & Yes & Yes & No & Yes & Yes \\
\hline Month $\times$ year of birth fixed effects & No & No & Yes & No & No & Yes & No & No & Yes \\
\hline
\end{tabular}

Notes: The dependent variable is neonatal mortality which is equal to 0 if the child survived the first month of life and 100 if they died, so that the coefficients are in percentage changes. All regressions control for state, year of birth and birth month fixed effects and a dummy variable for whether the child's eldest sibling was a boy, a dummy variable $=1$ if the child's household was upper caste.. Additional Time-series controls include the linear and quadratic state-specific trends in month of birth; world oil price and oil sample is limited to households in the lower three wealth quintiles; while in columns (7)-(9) the sample is limited to households within the upper two wealth quintiles. These are quintiles of an asset index created as the first principal component of a vector of assets. 
Table A.13: Sex Selection: By Wealth

\begin{tabular}{lcccccc}
\hline \hline & \multicolumn{2}{c}{ Full sample } & \multicolumn{2}{c}{ Poor } & \multicolumn{2}{c}{ Wealthy } \\
\hline & $(1)$ & $(2)$ & $(3)$ & $(4)$ & $(5)$ & $(6)$ \\
\hline$\Delta$ L(gold price) & -1.696 & -1.841 & -2.043 & -3.414 & -1.190 & 1.422 \\
& $(3.776)$ & $(3.747)$ & $(5.159)$ & $(5.215)$ & $(5.473)$ & $(4.534)$ \\
$\Delta$ L(gold price) $\times$ post-1985 & -6.990 & -9.311 & $-17.000^{*}$ & $-16.864^{*}$ & 6.714 & 4.092 \\
& $(7.116)$ & $(6.942)$ & $(9.712)$ & $(9.594)$ & $(10.188)$ & $(8.385)$ \\
\hline Sample mean & 47.893 & 47.893 & 48.326 & 48.326 & 47.288 & 47.288 \\
Marginal effect post-1985 & -8.686 & $-11.152^{*}$ & $-19.043^{* * *}$ & $-20.278^{* * *}$ & 5.523 & 5.514 \\
& $(6.049)$ & $(6.046)$ & $(8.220)$ & $(8.277)$ & $(8.770)$ & $(7.053)$ \\
Observations & 103171 & 103171 & 60137 & 60137 & 43034 & 43034 \\
Time-series controls & No & Yes & No & Yes & No & Yes \\
\hline \hline
\end{tabular}

Notes: The dependent variable is an indicator for the gender of the child being a girl, multiplied by 100. Sample is limited to second-born children born after 1985 in all the regressions. All regressions control for state, year of birth and birth month fixed effects, a dummy variable $=1$ if the child's household was upper caste and a dummy variable for whether the child's eldest sibling was a boy. Additional Time-series controls include the linear and quadratic state-specific trends in month of birth; world oil price; rainfall deviations from historical state-level mean in the month of birth,and their lags up to 12 months before birth. In columns (3)-(4), the sample is limited to households within the lower three wealth quintile; while in columns (5)-(6) the sample is limited to households within the upper two wealth quintiles. These are quintiles of an asset index created as the first principal component of a vector of assets. 


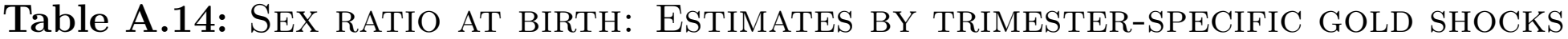

\begin{tabular}{|c|c|c|c|c|c|c|c|c|}
\hline \multirow[t]{2}{*}{ Time period: } & \multicolumn{2}{|c|}{ 1972-2005 } & \multicolumn{2}{|c|}{ Pre-1985 } & \multicolumn{2}{|c|}{ Post-1985 } & \multicolumn{2}{|c|}{ 1972-2005 } \\
\hline & (1) & $(2)$ & $(3)$ & (4) & $(5)$ & (6) & (7) & (8) \\
\hline$\Delta \mathrm{L}$ (gold price) in 3rd trimester & $\begin{array}{l}-4.158 \\
(3.415)\end{array}$ & $\begin{array}{l}-4.145 \\
(3.489)\end{array}$ & $\begin{array}{l}-0.537 \\
(3.861)\end{array}$ & $\begin{array}{l}-2.016 \\
(4.173)\end{array}$ & $\begin{array}{c}-12.221^{*} \\
(6.883)\end{array}$ & $\begin{array}{c}-13.341^{*} \\
(6.773)\end{array}$ & $\begin{array}{l}-2.027 \\
(3.895)\end{array}$ & $\begin{array}{l}-2.247 \\
(3.912)\end{array}$ \\
\hline$\Delta \mathrm{L}$ (gold price) in 2 nd trimester & $\begin{array}{l}-3.803 \\
(3.106)\end{array}$ & $\begin{array}{l}-3.637 \\
(3.205)\end{array}$ & $\begin{array}{l}-2.609 \\
(3.533)\end{array}$ & $\begin{array}{l}-5.140 \\
(3.803)\end{array}$ & $\begin{array}{l}-8.089 \\
(7.149)\end{array}$ & $\begin{array}{l}-7.502 \\
(7.086)\end{array}$ & $\begin{array}{l}-3.964 \\
(3.470)\end{array}$ & $\begin{array}{l}-3.351 \\
(3.566)\end{array}$ \\
\hline$\Delta \mathrm{L}$ (gold price) in 1st trimester & $\begin{array}{l}-0.432 \\
(3.272)\end{array}$ & $\begin{array}{c}0.185 \\
(3.380)\end{array}$ & $\begin{array}{l}-0.496 \\
(3.244)\end{array}$ & $\begin{array}{l}-0.117 \\
(3.608)\end{array}$ & $\begin{array}{l}-3.972 \\
(6.656)\end{array}$ & $\begin{array}{l}-3.408 \\
(6.748)\end{array}$ & $\begin{array}{c}0.121 \\
(3.733)\end{array}$ & $\begin{array}{c}0.912 \\
(3.801)\end{array}$ \\
\hline$\Delta \mathrm{L}($ gold price $)$ in 3 rd trimester $\times$ post -1985 & & & & & & & $\begin{array}{l}-9.217 \\
(7.840)\end{array}$ & $\begin{array}{l}-9.021 \\
(7.580)\end{array}$ \\
\hline$\Delta \mathrm{L}($ gold price $)$ in 2 nd trimester $\times$ post -1985 & & & & & & & $\begin{array}{l}-2.192 \\
(7.751)\end{array}$ & $\begin{array}{l}-3.889 \\
(7.674)\end{array}$ \\
\hline$\Delta \mathrm{L}($ gold price $)$ in 1 st trimester $\times$ post -1985 & & & & & & & $\begin{array}{l}-3.120 \\
(7.673)\end{array}$ & $\begin{array}{l}-3.847 \\
(7.644)\end{array}$ \\
\hline Sample mean & 47.893 & 47.893 & 48.248 & 48.248 & 47.750 & 47.750 & 47.893 & 47.893 \\
\hline Marginal effect of 3rd trimester shocks post-1985 & & & & & & & $\begin{array}{c}-11.244 \\
(6.858)\end{array}$ & $\begin{array}{c}-11.267^{*} \\
(6.700)\end{array}$ \\
\hline Marginal effect of 2rd trimester shocks post-1985 & & & & & & & $\begin{array}{l}-6.156 \\
(7.005)\end{array}$ & $\begin{array}{l}-7.240 \\
(7.002)\end{array}$ \\
\hline Marginal effect of 1 st trimester shocks post-1985 & & & & & & & $\begin{array}{l}-2.999 \\
(6.679)\end{array}$ & $\begin{array}{l}-2.935 \\
(6.741)\end{array}$ \\
\hline Observations & 103171 & 103171 & 29651 & 29651 & 73520 & 73520 & 103171 & 103171 \\
\hline
\end{tabular}

Notes: The table shows results of estimating specification 2 where the dependent variable is an indicator for the gender of the child being a girl, multiplied by 100. Sample is limited to second-born children in all the regressions. $\Delta \mathrm{L}$ (gold price) is the change in log of the average gold price in the 1st, 2nd or 3rd trimester of pregnancy, relative to the previous 3 months. Gold prices are in USD, deflated using US CPI. All regressions control for state, year of birth and birth month fixed effects, a dummy variable $=1$ if the child's household was upper caste and a dummy variable for whether the child's eldest sibling was a boy. Additional "Time-series controls" include the linear and quadratic state-specific 12 mecific trends in month of birth, word oil price, rainfall deviations from historical state-level mean in the mont of birth and their lags up to 12 month preceding the birth. In Panel B, "first son" is a dummy variable $=1$ if the eldest sibling of the child (i.e. the first-born child of the parents of the child) is a boy, and 0 otherwise. Standard errors are clustered by month $\times$ year of birth. 


\section{B Appendix: Conceptual Framework}

In this section we sketch two simple models. In the first, parents value the welfare of their children equally, but are obliged by convention to pay dowry when their daughter's marry and this raises the cost of daughters. In the second, there is exogenous son preference i.e. parents attach greater weight to the welfare of sons but there is no dowry and gold is simply a commodity that parents consume. In the first model, an increase in the relative price of dowry raises excess girl mortality and in the second, income effects of gold price can generate excess girl mortality (among net purchasers of gold) as long as parents prefer sons. ${ }^{37}$

\section{B.1 Case I: Gold for Dowry}

Parents have utility $u(x, w)$, where $x$ is consumption of a numeraire good and $w$ is child welfare, and they earn income $y$. The real price of gold is $p$. Child welfare $w$ is produced using gold and consumption as inputs. The effective price of $w$ is $a+b p$, where $a>0$ is a constant, $b>0$ if the child is a girl and a dowry is paid at her marriage, and $b<0$ if the child is a boy and he receives a dowry at marriage. If parents have rational expectations and gold prices follow a random walk then w will respond to the current gold price.

If we assume a Cobb-Douglas parental utility function so that $u(x, w)=x^{\alpha} w^{1-\alpha}$, the optimal investment in child welfare is:

$$
w^{*}(p)=\frac{y}{(1-\alpha)(a+b p)}
$$

so that the comparative statics yield $\left(\partial w^{*} / \partial p\right)<0$ if the child is a girl, and $\left(\partial w^{*} / \partial p\right)>0$ if the child is a boy. We are assuming that $\mathrm{b}$ does not adjust to changes in $\mathrm{p}$, for example because social norms dictate the content of dowry. We test this and the random walk assumptions.

\section{B.2 Case II: Gold for Consumption}

We now switch off the dowry channel by assuming that parents consume gold for other reasons, such as to gain social status by exhibiting jewelry. Parental utility is given by $u(x, g, \theta w)$, where $\theta$ measures preference for children, and is exogenously higher for sons than daughters, $\mathrm{g}$ is the quantity of gold and $\mathrm{p}$ is its current price. In the absence of dowry, the price of child welfare $w$ is a constant $a$. Households respond to the current gold price $p$. Let $z=\theta w$, or "effective" child welfare, be the choice variable. The Slutsky equation for an increase in the gold price is then:

$$
\frac{\partial z}{\partial p}=\frac{\partial h}{\partial p}-\frac{\partial z}{\partial y} g
$$

\footnotetext{
${ }^{37}$ We are grateful to Selma Walther for suggesting this model sketch.
} 
If households are large net gold buyers, the income effect may dominate the substitution effect and we will then have $\frac{\partial z}{\partial p}<0$. The impact of actual child welfare is:

$$
\frac{\partial w}{\partial p}=\frac{1}{\theta} \frac{\partial z}{\partial p}
$$

which is less negative for boys than for girls. Hence income effects of gold price increases can generate excess girl mortality in the absence of dowry. However this mechanism would lead to boys also having higher mortality as a result of gold price increases; a prediction that is rejected in the data. 